Article

\title{
Net Surface Shortwave Radiation from GOES \\ Imagery-Product Evaluation Using Ground-Based Measurements from SURFRAD
}

\section{Anand K. Inamdar ${ }^{1,2, *}$ and Pierre C. Guillevic ${ }^{3}$}

1 Cooperative Institute for Climate and Satellites (CICS), North Carolina State University, Asheville, NC 28801, USA

2 NOAA's National Centers for Environmental Information, Asheville, NC 28801, USA

3 Jet Propulsion Laboratory, California Institute of Technology, Pasadena, CA 91011, USA; E-Mail: Pierre.Guillevic@gmail.com

* Author to whom correspondence should be addressed; E-Mail: anand.inamdar@ noaa.gov; Tel.: +1-828-271-4437.

Academic Editors: Richard Müller and Prasad S. Thenkabail

Received: 1 May 2015 / Accepted: 12 August 2015 / Published: 21 August 2015

\begin{abstract}
The Earth's surface net radiation controls the energy and water exchanges between the Earth's surface and the atmosphere, and can be derived from satellite observations. The ability to monitor the net surface radiation over large areas at high spatial and temporal resolution is essential for many applications, such as weather forecasting, short-term climate prediction or water resources management. The objective of this paper is to derive the net surface radiation in the shortwave domain at high temporal (half-hourly) and spatial resolution $(\sim 1 \mathrm{~km})$ using visible imagery from Geostationary Operational Environmental Satellite (GOES). The retrieval algorithm represents an adaptation to GOES data of a standard algorithm initially developed for the NASA-operated Clouds and Earth's Radiant Energy System (CERES) scanner. The methodology relies on: (1) the estimation of top of atmosphere shortwave radiation from GOES spectral measurements; and (2) the calculation of net surface shortwave (SW) radiation accounting for atmospheric effects. Comparison of GOES-retrieved net surface shortwave radiation with ground-measurements at the National Oceanic and Atmospheric Administration's (NOAA) Surface Radiation (SURFRAD) stations yields very good agreement with average bias lower than $5 \mathrm{~W} \cdot \mathrm{m}^{-2}$ and root mean square difference around $70 \mathrm{~W} \cdot \mathrm{m}^{-2}$. The algorithm performance is usually higher over areas characterized by low spatial variability in term of land cover type and surface biophysical
\end{abstract}


properties. The technique does not involve retrieval and assessment of cloud properties and can be easily adapted to other meteorological satellites around the globe.

Keywords: geostationary operational environmental satellite (GOES); clouds and earth's radiant energy systems (CERES); net surface solar radiation retrievals

\section{Introduction}

The net surface radiation controls the energy and water exchanges between the biosphere and the atmosphere, and has major influences on the Earth's weather and climate [1]. Therefore, the ability to better monitor each of the shortwave and long wave radiative components at the surface is essential to better understand existing feedbacks between the surface energy and hydrological cycles, and to better assess future effects of climate change. The Earth's surface net shortwave (SW) radiation, i.e., the difference between the incoming and outgoing SW radiation, represents the amount of solar radiation absorbed by the surface and can be derived from satellite observations.

A very comprehensive review of various methods available to retrieve net surface energy budget is provided in a recent paper [2]. Ground measurements of surface radiation balance have been available since the mid-1960s. Presently, there is vast network of thousands of such stations distributed over different climate regimes of the globe [3-5] employing state-of-the-art instrumentation and providing accuracies ranging from $2 \%$ to $5 \%$ in the surface insolation. These have been used mainly for evaluating surface radiation products derived from other methods.

Bulk of the methods providing global coverage of the surface radiation are based on satellite remote sensing. Prior to the advent of the Earth Observation from Space (EOS) era in late 1990s, retrieval schemes employed either the geostationary satellites [6-12] or the National Oceanic and Atmospheric Administration (NOAA) - operated suite of polar orbiters [13,14]. Methods used ranged from statistical/empirical schemes [6] to physically-based [7-11]. The physically-based methods involve use of a complete radiative transfer model using satellite-retrieved physical properties of surface, atmosphere and clouds. The International Satellite Cloud Climatology Project (ISCCP) has produced a 25-year record of global radiative fluxes called ISCCP FD [15] at three hour intervals on a $280 \mathrm{~km}$ equal area grid, through employing ISCCP-generated inputs. Another important long-term data set, the Global Energy and Water Cycle Experiment (GEWEX) [16] surface radiation budget (SRB) employed a combination of different schemes in the shortwave (SW) and long wave (LW) using cloud parameters derived from the ISCCP — DX data as input along with atmospheric profiles taken from a 4-D data assimilation. An earlier simplified version of the GEWEX algorithm [8] produced hourly and daily insolation products over the continental United States, which has been later validated [17] using ground measurements at the U. S. Climate Reference Network (USCRN) sites. Detailed reviews of these methods have been provided in $[2,13,18]$.

The first broadband radiometer instrument, Earth radiation Budget (ERB), flew on board the Nimbus-7 [19] followed by the Earth Radiation Budget Experiment (ERBE) [20] in 1985. Following a gap of eight years, the next generation of broadband radiometer instrument Cloud and Earth's Radiant Energy System instrument (CERES) was launched in late 1997 and has continued measurements 
on-board the EOS Terra and Aqua missions [21]. The launch of broadband sensors triggered a whole new set of improved algorithms to be designed to estimate the top of atmosphere (TOA) to surface radiation budgets [21-23]. For instance, the CERES algorithm convolves the cloud and aerosol properties derived from the Moderate Resolution Imaging Spectroradiometer (MODIS) instrument also on-board the EOS platform into the CERES field of view, which are then employed to produce surface radiation budgets at a spatial resolution of about $20 \mathrm{~km}$. through constraining the TOA broadband radiation fluxes [21]. The cloud and atmosphere properties information may also be derived from other sources such as ISCCP. However, the spatial resolution of surface radiation budgets retrieved from broadband sensors such as ERBE and CERES range from $20 \mathrm{~km}$ to $45 \mathrm{~km}$, which is still inadequate for some applications such as water resources management in agriculture and resolving differences at the ecosystem level or bridge the gap between coarse-resolution surface radiation products and point-scale ground measurements. A direct method of estimating the net surface SW radiation at $1 \mathrm{~km}$ spatial scale was developed [24] using a narrow-band to broadband conversion of albedo from multispectral MODIS data. A recent study [25] attempted a hybrid method linking the net surface SW radiation with the Landsat TOA reflectance to produce high-resolution maps of surface net SW radiation. While the last two methods fulfill the high spatial resolution requirement, they lack the temporal resolution necessary to construct a diurnal cycle or daily averages.

In the present study, we employ an approach of using established relationships between the TOA and surface SW radiation budget [23] employed detailed radiative transfer calculations to infer such a relationship between the top of atmosphere (TOA) SW radiation and the solar flux absorbed by the surface depending on solar zenith angle and the column water vapor amount in the atmosphere. The algorithm developed by [23] is currently an operational component of the CERES processing sub-system 4.6. The algorithm was later improved upon by [26] to account for variations in atmospheric properties, such as aerosol optical depth, ozone concentration, surface pressure and cloud height. The improved parameterization performed well under both clear and cloudy sky conditions when compared to ground-based measurements using radiometers mounted on field towers near Boulder, CO [26].

This paper presents a methodology to derive the net surface radiation in the SW domain at high temporal (half-hourly) and spatial resolution ( $\sim \mathrm{km}$ at nadir) using visible imagery from Geostationary Operational Environmental Satellite (GOES). The retrieval algorithm represents an adaptation to GOES data of the standard algorithm initially developed for CERES data [23,26]. We propose to: (1) develop a relationship between GOES spectral radiometric measurements and TOA SW radiative fluxes measured by CERES depending on surface vegetation density information from satellite-based Normalized Difference Vegetation Index (NDVI); and to (2) derive surface net radiation from top of atmosphere SW radiation estimates accounting for atmospheric effects. The performance of the algorithm is evaluated using ground-based measurements from the NOAA's Surface Radiation (SURFRAD) observational network [5,27]. A similar analysis has been performed with standard SW radiation budget products derived from CERES at around $20 \mathrm{~km}$ spatial resolution to illustrate the relative performance of both algorithms in comparison with ground-based measurements. However, due to the vastly different spatial and temporal resolution of the two sensors, it needs to be emphasized that we are not cross-comparing the performance of GOES-retrievals with CERES, but only with ground measurements. The data and methodology used in this study are described in Sections 2 and 3, respectively. Results are presented and discussed in Section 4 along with comparative error statistics from similar studies cited above. 


\section{Data Description}

\subsection{Satellite Data}

The methodology (Figure 1) is based on multi-sensor measurements made by the visible imagers onboard the GOES-10 and GOES-12 satellites for the years 2003 and 2007 respectively, and by the CERES instrument onboard the Earth Observing System (EOS) Terra and Aqua satellites. The retrieval algorithm uses visible imagery in the $0.55-0.75 \mu \mathrm{m}$ spectral domain measured by GOES sensors at half-hourly intervals and full native spatial resolution (1 km at nadir). GOES-10 served as GOES-West geostationary satellite from July 1998 until July 2006, while GOES-12 served as the GOES-East satellite from March 2003 until April 2010. GOES data for the years 2003 and 2007 are archived and distributed by the NOAA's Comprehensive Large-Array Data Stewardship System (CLASS) at http://www.class.ncdc.noaa.gov.

To derive top of atmosphere shortwave radiation from GOES observations, we use broadband measurements from CERES shortwave channel (from 0.3 to $5 \mu \mathrm{m}$ ) with a spatial resolution of around $20 \mathrm{~km}$ at nadir. The net surface radiation products from CERES are also used in the validation process. The CERES Single Satellite Footprint (SSF) data (Edition 3A) representing instantaneous measurements of TOA SW radiation, the parameterized surface net radiation, and solar and viewing geometry parameters used in this study are distributed by the Langley Research Center Atmospheric Science Data Center (LaRC ASDC) at http://eosweb.larc.nasa.gov.

\subsection{Ancillary Data}

The column water vapor and the aerosol optical depth (AOD) at $550 \mathrm{~nm}$ represent the ancillary data required by the methodology. We used water vapor derived from the Moderate Resolution Imaging Spectroradiometers (MODIS) on board EOS Terra and Aqua platforms. The standard MODIS column water vapor product (named MOD05_L2) has a spatial resolution of around $5 \mathrm{~km}$. Water vapor products retrieved under clear-sky conditions have been interpolated to correspond to the GOES observation times. The aerosol optical depth level-3 product has been derived from the Multi-angle Imaging Spectroradiometer (MISR) on board the EOS Terra employing the Giovanni-Interactive Visualization and Analysis tool (http://gdata1.sci.gsfc.nasa.gov/daac-bin/G3/gui.cgi?instance_id=MISR_Daily_L3) over a $0.5 \times 0.5$ domain surrounding each ground validation site. In cases where no MISR retrievals were available, the domain around the site was expanded until an adequate number of time samples (at least about 5 in a month) were available. Ground-based aerosol optical depth measurements derived from the multi-channel Multifilter Rotating Shadowband Radiometer (MFRSR) [5] were available for most of the selected sites except the Southern Great Plains site in Oklahoma. Results based on MFRSR AODs were also obtained for comparison and diagnostic studies.

The relationship between the CERES TOA radiative fluxes and GOES visible raw counts depends on surface vegetation density. In this study, we have used NDVI gridded products from MODIS collection-5 (MOD13C2) at $1 \mathrm{~km}$ spatial resolution. Also, for validation purpose, we have used MODIS collection-5 surface albedo products at $500 \mathrm{~m}$ spatial resolution and NDVI products at $250 \mathrm{~m}$ resolution to evaluate the spatial representativeness of ground-based measurements. The MODIS products used in 
this study are distributed by NASA's Earth Observing System Data and Information System (http://earthdata.nasa.gov).

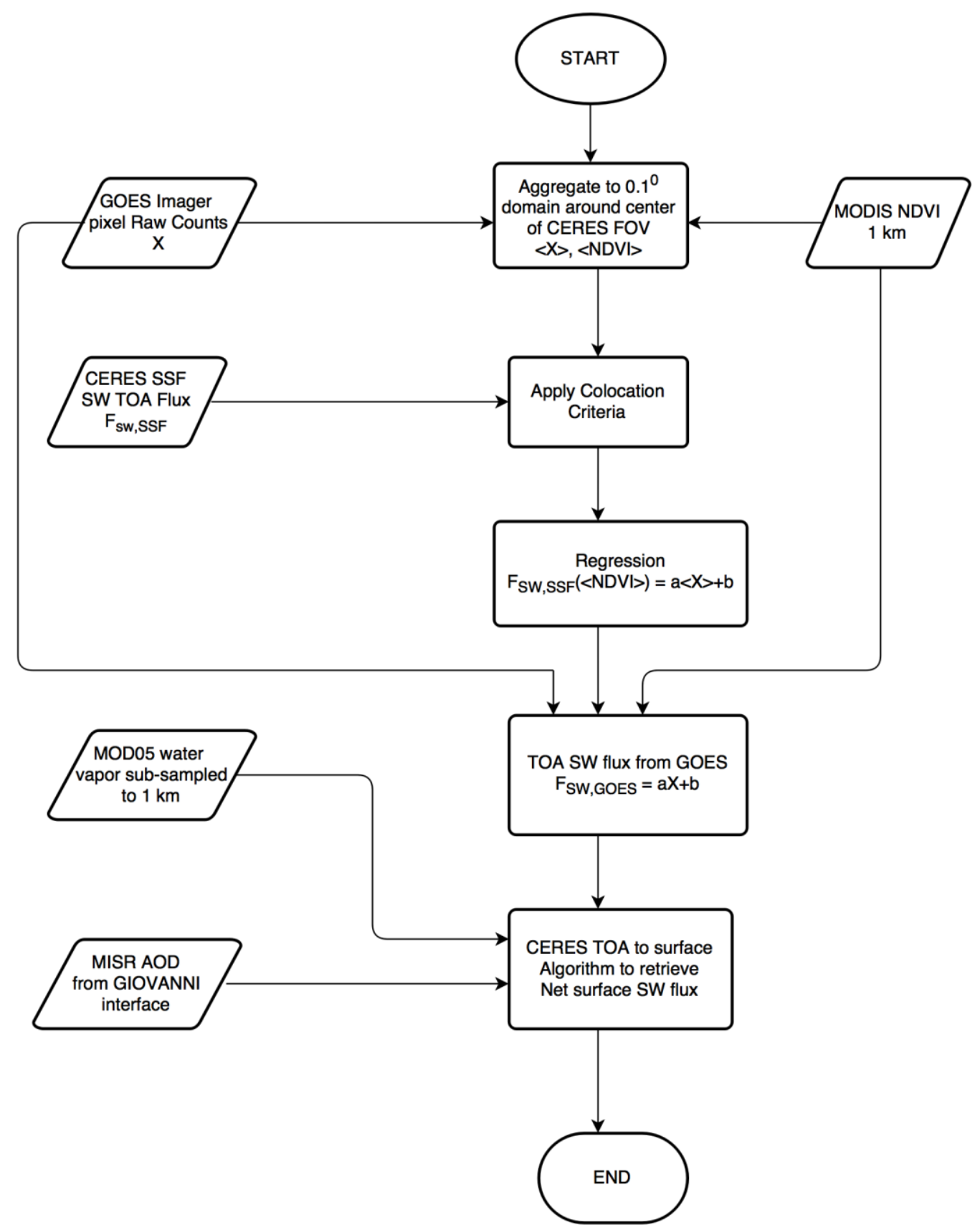

Figure 1. Flowchart depicting the methodology of retrieving net surface flux from GOES imagery. Parameters shown within $<>$ represent average values over domain.

\subsection{Ground-Based Data}

Ground-based measurements from eight different sites of the CERES Atmospheric Radiation Measurement (ARM) Validation Experiment (CAVE, http://www-cave.larc.nasa.gov/cave/) covering fall, winter, spring and summer periods for the year 2003 and 2007 have been used to evaluate the uncertainties associated with GOES-derived surface net SW radiation retrievals. In addition to radiation data, the CAVE dataset also provides the surface meteorology and aerosol optical depths when available. 
The selected sites are part of the Surface Radiation (SURFRAD) observation network $([5,27])$ operated by NOAA (Table 1). The eight sites are located near Lamont, OK in the Southern Great Plains (referred as SGP hereafter), Desert Rock, NV (DRA), Table Mountain near Boulder, CO (BOS), Bondville, IL (BON), Fort Peck, MT (FPK), Sioux Falls, SD (SXF), Goodwin Creek, MS (GCR), and Penn State, PA (PSU). These sites represent a variety of surface types and climate conditions: grassland, agricultural landscape, arid area and high elevation grassland.

Table 1. List of Surface Radiation (SURFRAD) sites including geo-location, elevation, and basic description of the surface type at station location and around the station within Geostationary Operational Environmental Satellite (GOES) footprints.

\begin{tabular}{ccccccc}
\hline Site Location & Id & Latitude & Longitude & Elevation & $\begin{array}{c}\text { Surface Type } \\
\text { at Station }\end{array}$ & $\begin{array}{c}\text { Surface Type } \\
\text { around Station }\end{array}$ \\
\hline Table Mountain, CO & BOS & $40.126 \mathrm{~N}$ & $105.238 \mathrm{~W}$ & $1692 \mathrm{~m}$ & Sparse grassland & Grassland/crop \\
Bondville, IL & BON & $40.051 \mathrm{~N}$ & $88.373 \mathrm{~W}$ & $213 \mathrm{~m}$ & Grassland & Cropland \\
Goodwin Creek, MS & GCR & $34.255 \mathrm{~N}$ & $89.873 \mathrm{~W}$ & $96 \mathrm{~m}$ & Grassland & Grassland \\
Fort Peck, MT & FPK & $48.308 \mathrm{~N}$ & $105.102 \mathrm{~W}$ & $636 \mathrm{~m}$ & Grassland & Grassland \\
Desert Rock, NV & DRA & $36.623 \mathrm{~N}$ & $116.020 \mathrm{~W}$ & $1004 \mathrm{~m}$ & Arid shrubland & Arid shrubland \\
ARM Great Plains, OK & SGP & $36.604 \mathrm{~N}$ & $97.485 \mathrm{~W}$ & $314 \mathrm{~m}$ & Grassland & Grassland \\
Penn State U., PA & PSU & $40.720 \mathrm{~N}$ & $77.931 \mathrm{~W}$ & $373 \mathrm{~m}$ & Cropland & Cropland/forest \\
Sioux Falls, SD & SXF & $43.734 \mathrm{~N}$ & $96.623 \mathrm{~W}$ & $483 \mathrm{~m}$ & Grassland & Grassland/urban \\
\hline
\end{tabular}

The primary measurements used to derive the net SW radiation are the upwelling and downwelling shortwave irradiances that are measured by two ground-based pyranometers (model Precision Spectral Pyranometer from the Eppley Laboratory). The Precision Spectral Pyranometer is a World Meteorological Organization First Class Radiometer designed for the measurement of sun and sky radiation in the spectral range from 0.285 to $2.8 \mu \mathrm{m}$. The instrument is intended to weight the energy flux in all wavelengths equally. The height of the radiation measurements (downwelling and outgoing) for the SURFRAD sites is around $9 \mathrm{~m}$, and the spatial representativeness of the measurements is around $70 \times 70 \mathrm{~m}^{2}$. The surface net $\mathrm{SW}$ radiation represents the difference between incoming and outgoing shortwave radiation. All pyranometers have been calibrated to world standards at the World Radiation Center in Davos, Switzerland and yield accuracies of $11 \mathrm{~W} \cdot \mathrm{m}^{-2}$ compared to the reference. SURFRAD stations are programmed to sample at 15 -second intervals and to provide one-minute averages of each parameter. All instruments have been meticulously maintained, and are replaced on an annual basis with freshly calibrated instruments [5,27]. A chronological record of all instruments is continuously updated and available on the SURFRAD website at http://www.srrb.noaa.gov/surfrad.

\section{Methodology}

The methodology used to retrieve surface net SW radiative budget from GOES visible imagery relies on two main steps: (1) the estimation of TOA broadband SW radiation from GOES narrow visible band; and (2) the computation of surface net SW radiation from TOA flux accounting for atmospheric effects $[23,26]$. A flowchart of the methodology is shown in Figure 1. 


\subsection{Top-of-Atmosphere SW Radiation from GOES Visible Imagery}

TOA SW radiation products at $1 \mathrm{~km}$ spatial resolution $\left(F_{S W, G O E S}\right)$ are derived from GOES raw visible counts $(X)$ using a linear relationship Equation (1). First, the relationship is calibrated using linear regressions between CERES TOA SW fluxes and GOES visible raw counts aggregated at CERES spatial resolution. Then, the relation derived at CERES resolution is used at higher resolution to estimate the broadband TOA SW radiative flux at $1 \mathrm{~km}$ resolution using GOES raw measurements in 10-bit counts as input.

$$
F_{S W, G O E S}=a_{i} X+b_{i}
$$

where $F_{S W, G O E S}\left(\mathrm{~W} \cdot \mathrm{m}^{-2}\right)$ is TOA SW flux retrieved from GOES imager, and $\boldsymbol{a}_{\boldsymbol{i}}$ is the regression slope $\left(\mathrm{W} \cdot \mathrm{m}^{-2}\right.$ per count) and $\boldsymbol{b}_{\boldsymbol{i}}$ is the regression intercept $\left(\mathrm{W} \cdot \mathrm{m}^{-2}\right)$ defined for each class of vegetation density $i$. In this study, we have considered 5 different classes of NDVI values ( $i$ varies from 1 to 5 ) to represent different range of vegetation densities. This classification is used to partially account for significant differences between spectral responses of bare soils and vegetation in the shortwave domain. Regression coefficients obtained for each class of NDVI are presented in Table 2.

The determination of the regression coefficients $a_{i}$ and $b_{i}$ Equation (1) requires collocated and simultaneously acquired CERES and GOES observations. For each pair of satellite observations, the matching is done conforming to the following criteria:

The GOES pixels at native resolution and also the $1 \mathrm{~km}$ NDVI are aggregated over a domain of 0.1 degree in latitude-longitude centered on the CERES footprint centers. No convolution with the CERES point spread function has been performed;

- The time difference between observation times for CERES and GOES is less than 15 minutes;

- The difference in viewing zenith angles between the two instruments is less than 10 degrees to reduce directional effects;

- The standard deviation of the radiances of GOES pixels within the bounding CERES coarser pixel is less than $10 \%$ of the domain mean value;

- The difference between the maximum and the minimum count values in the GOES domain is less than $20 \%$ of the domain mean value to avoid mixed pixels and undetected clouds.

Because clouds can move at $1 \mathrm{~km} \cdot \mathrm{min}^{-1}$ ( or $1 \mathrm{GOES}$-pixel $\mathrm{min}^{-1}$ ) even at nominal wind speeds, the last two criteria allow us to evaluate and eliminate image pairs with rapidly changing dynamic features, which can introduce significant inhomogeneity.

The CERES instrument measures directional radiances according to solar and viewing geometry. Conversion of directional radiance into radiative flux is performed using the Angular Directional Models (ADM) [22]. These models are empirical formulations which account for the radiance anisotropy. They depend on the surface type, the viewing and solar geometries and cloud properties. In this study, we found that the performance of the calibration and the quality of the correlation remained similar whether the flux or the radiance was used for the matching. It should be emphasized that this does not deny the value of ADMs in the conversion of instrument-measured radiance to flux. However, the use of the ADMs in post-match processing may introduce additional uncertainties without adding significant benefit. 
Table 2. Regression coefficients to convert 10-bit GOES-10 (year 2003) and GOES-12 (year 2007) raw visible counts to top of atmosphere (TOA) flux in $\mathrm{W} \cdot \mathrm{m}^{-2}$ using Equation (1).

\begin{tabular}{|c|c|c|c|}
\hline Time Period & NDVI Range & $\mathbf{a}_{\mathbf{i}}$ & $\mathbf{b}_{\mathbf{i}}$ \\
\hline \multirow{5}{*}{ January 2003} & $0-0.2$ & 1.65719 & -27.3673 \\
\hline & $0.2-0.4$ & 1.61759 & -12.3210 \\
\hline & $0.4-0.6$ & 1.54969 & 6.22673 \\
\hline & $0.6-0.8$ & 1.41607 & 33.0425 \\
\hline & $0.8-1$ & 1.39171 & 47.3000 \\
\hline \multirow{5}{*}{ April 2003} & $0-0.2$ & 1.56215 & -10.0458 \\
\hline & $0.2-0.4$ & 1.60944 & 2.17288 \\
\hline & $0.4-0.6$ & 1.57611 & 14.2872 \\
\hline & $0.6-0.8$ & 1.54356 & 22.2742 \\
\hline & $0.8-1$ & 1.56982 & 20.1361 \\
\hline \multirow{5}{*}{ July 2003} & $0-0.2$ & 1.36977 & 24.9856 \\
\hline & $0.2-0.4$ & 1.37399 & 36.0040 \\
\hline & $0.4-0.6$ & 1.37690 & 46.3613 \\
\hline & $0.6-0.8$ & 1.42964 & 47.2493 \\
\hline & $0.8-1$ & 1.55444 & 40.0413 \\
\hline \multirow{5}{*}{ October 2003} & $0-0.2$ & 1.62060 & -48.4116 \\
\hline & $0.2-0.4$ & 1.63388 & -26.9151 \\
\hline & $0.4-0.6$ & 1.57763 & -2.05015 \\
\hline & $0.6-0.8$ & 1.54057 & 0.907330 \\
\hline & $0.8-1$ & 1.49174 & 6.79135 \\
\hline \multirow{5}{*}{ January 2007} & $0-0.2$ & 1.51263 & 3.08094 \\
\hline & $0.2-0.4$ & 1.49472 & 16.4533 \\
\hline & $0.4-0.6$ & 1.41974 & 41.7793 \\
\hline & $0.6-0.8$ & 1.37287 & 47.7901 \\
\hline & $0.8-1$ & 1.34116 & 48.9031 \\
\hline \multirow{5}{*}{ April 2007} & $0-0.2$ & 1.45888 & 22.5837 \\
\hline & $0.2-0.4$ & 1.47451 & 24.1078 \\
\hline & $0.4-0.6$ & 1.43005 & 37.4279 \\
\hline & $0.6-0.8$ & 1.39888 & 51.0193 \\
\hline & $0.8-1$ & 1.35463 & 58.8031 \\
\hline \multirow{5}{*}{ July 2007} & $0-0.2$ & 1.23009 & 60.8305 \\
\hline & $0.2-0.4$ & 1.33400 & 45.1453 \\
\hline & $0.4-0.6$ & 1.35972 & 43.9316 \\
\hline & $0.6-0.8$ & 1.39614 & 54.5158 \\
\hline & $0.8-1$ & 1.38649 & 62.9358 \\
\hline \multirow{5}{*}{ October 2007} & $0-0.2$ & 1.50868 & -3.66579 \\
\hline & $0.2-0.4$ & 1.45991 & 15.7038 \\
\hline & $0.4-0.6$ & 1.45392 & 26.4691 \\
\hline & $0.6-0.8$ & 1.39778 & 39.0930 \\
\hline & $0.8-1$ & 1.39148 & 49.0610 \\
\hline
\end{tabular}




\subsection{TOA to Surface Net SW Radiation Algorithm}

In the CERES processing chain, the surface net SW radiation can be derived from TOA outgoing SW radiation using two different retrieval algorithms. The first algorithm was developed by [23]. This model used only a moderately absorbing haze model aerosol. The parameterization [23] was further modified to account for different types of absorbing aerosols over various surface types [26]. This model is referred to as "Model A" in the CERES community and although designed for use under all-sky conditions, it has been used in operational production of only clear-sky net SW flux at the surface. The second algorithm, usually referred to as "Model B" or the Langley-parameterized shortwave algorithm (LPSA), was developed at the Langley Research Center [28] is being used to retrieve the downward SW flux under both clear and cloudy sky conditions. These schemes have been extensively validated against ground measurements worldwide covering different geographical domains, land surface types and seasons [29]. The uncertainty of the net surface SW flux derived from either model A or model B is around $20 \mathrm{~W} \cdot \mathrm{m}^{-2}$ [29].

In this study, we have used the algorithm refered to as "Model A" [23,26] above, but under all sky conditions instead of only "clear skies" used by the CERES sub-system. Based on a radiative transfer model, the algorithm estimates the fraction of solar radiation absorbed by the surface $\left(a_{S W}\right)$ for a large set of surface and atmospheric conditions, and estimates the net $\mathrm{SW}$ flux, $\Delta F_{S W}$, at the surface Equation (2).

$$
\Delta F_{S W}=a_{S W} E_{0} \mu / d^{2} \text { with } a_{S W}=\alpha(\mu, w)-\beta(\mu, w) r \text { and } r=F_{S W, G O E S} \frac{d^{2}}{E_{0} \mu}
$$

where $\Delta F_{S W}$ is the net surface $\mathrm{SW}$ radiation flux, $E_{0}$ is the incoming solar radiation, $r$ is the TOA albedo (see below), $d$ is the mean earth-sun distance in normalized astronomical units, and $\alpha$ and $\beta$ are empirical functions of the cosine of solar zenith angle $(\mu)$ and column water vapor amount $(w)$-see [23,26] - for more details. The TOA SW flux from GOES, $F_{S W, G O E S}$, is derived from Equation (1). The regression coefficients have been provided for ocean/ice, ocean/land and ocean/land/ice cases $[23,26]$. Although the use of the appropriate set of coefficients is preferred when the nature of the underlying surfaces are known, the coefficients for the ocean/land/ice category have been used in this study.

\section{Results and Discussion}

\subsection{TOA Outgoing Shortwave Radiation from GOES}

The relationship between the outgoing CERES-measured SW radiation and aggregated GOES visible raw counts has been calibrated using matched observations as described in the previous section under all-sky conditions. The correlations between the CERES TOA SW flux and the aggregated GOES raw counts were performed for five different equal intervals of NDVI between 0 and 1 (see Table 2). The correlations were more than 0.9 for each of the cases reported in Table 2. Figure 2 shows the variation of GOES-12 raw counts (10-bit numbers varying from 0 to 1023) against the collocated CERES TOA SW radiative flux for the month of July 2007 for two different interval ranges of NDVI (0-0.2 and 0.6-0.8). The correlation between the two products is higher than 0.94 . The net surface SW radiation is 
then estimated from the GOES-retrieved TOA flux using equation through applying the parameterization scheme [26].

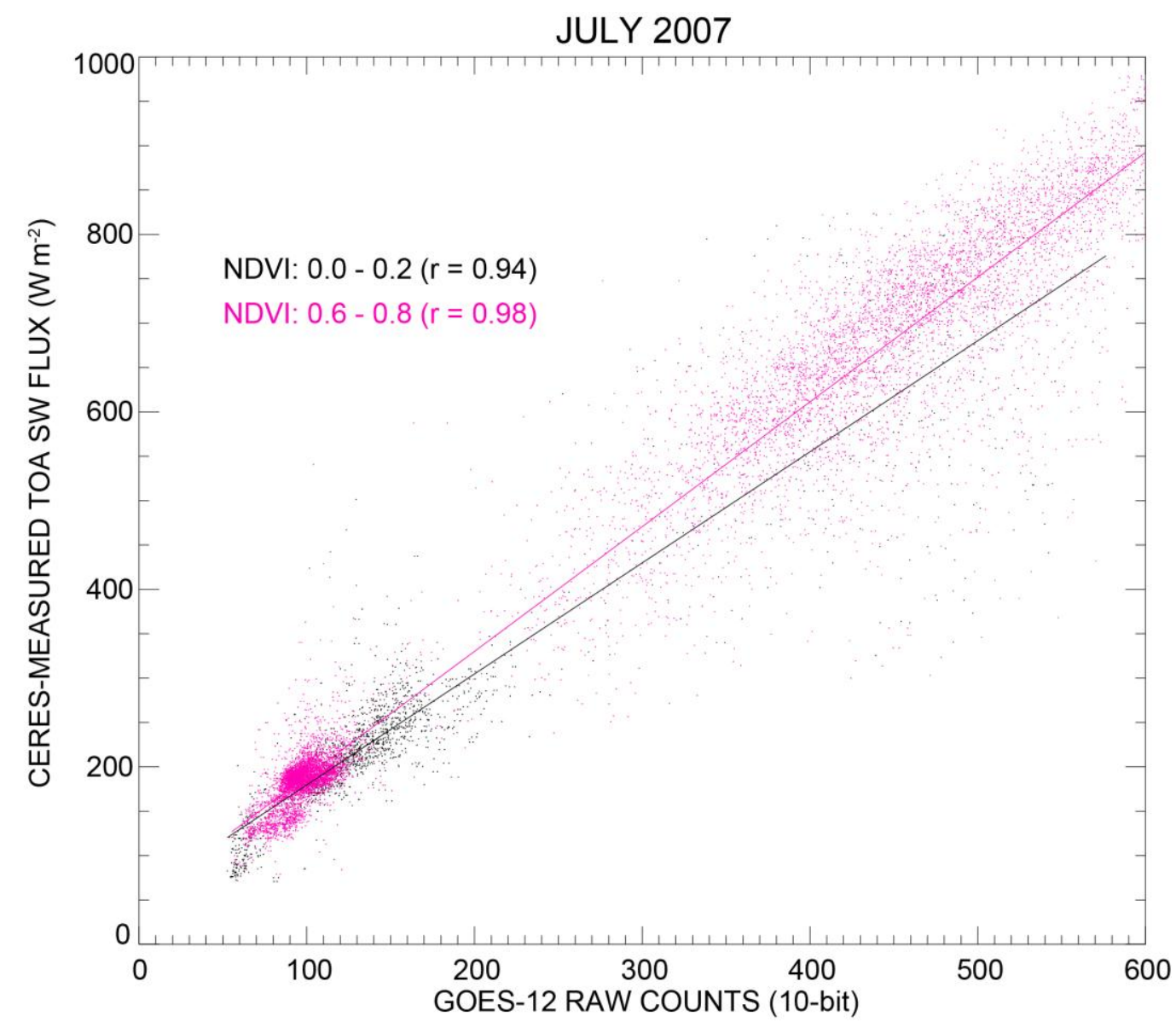

Figure 2. Matched pairs of GOES-12 raw counts (abscissa) and Clouds and Earth's Radiant Energy System (CERES)-measured TOA shortwave (SW) flux for July 2007 for two different Normalized Difference Vegetation Index (NDVI) intervals. Pearson's Correlation (r) value obtained between satellite data are represented.

\subsection{Validation Results}

The uncertainties of net SW radiation retrieved from GOES have been evaluated using ground-based measurements collected at all eight selected sites (Figures 3-5 and Table 3) for the years 2003 and 2007. Overall, comparisons between GOES-retrieved and ground-based net surface shortwave radiation yield very good agreement with average bias lower than $5 \mathrm{~W} \cdot \mathrm{m}^{-2}$ and root mean square difference of around $70 \mathrm{~W} \cdot \mathrm{m}^{-2}$. Time series comparison at Lamont, OK (SGP site) (Figure 3, top panel) for 5 days between days 181-186 shows very good agreement between ground-based and GOES-derived surface net SW radiation budget with a mean bias of around $7 \mathrm{~W} \cdot \mathrm{m}^{-2}$. Each of the GOES-retrieved (black dots) and CERES Model B values (magenta-colored symbols) for the full month of July 2003 have been paired up with ground measurements and shown as a scatter plot (bottom panel).

Figure 4 shows results for all eight surface stations combined in a single plot and presented for each month of January, April, July and October of the years 2003 and 2007 in Figure 4a,b respectively. 
A detailed break-up of results by station, month and year are also presented in Table 3. Salient features of these results are discussed in more detail in the following paragraphs.
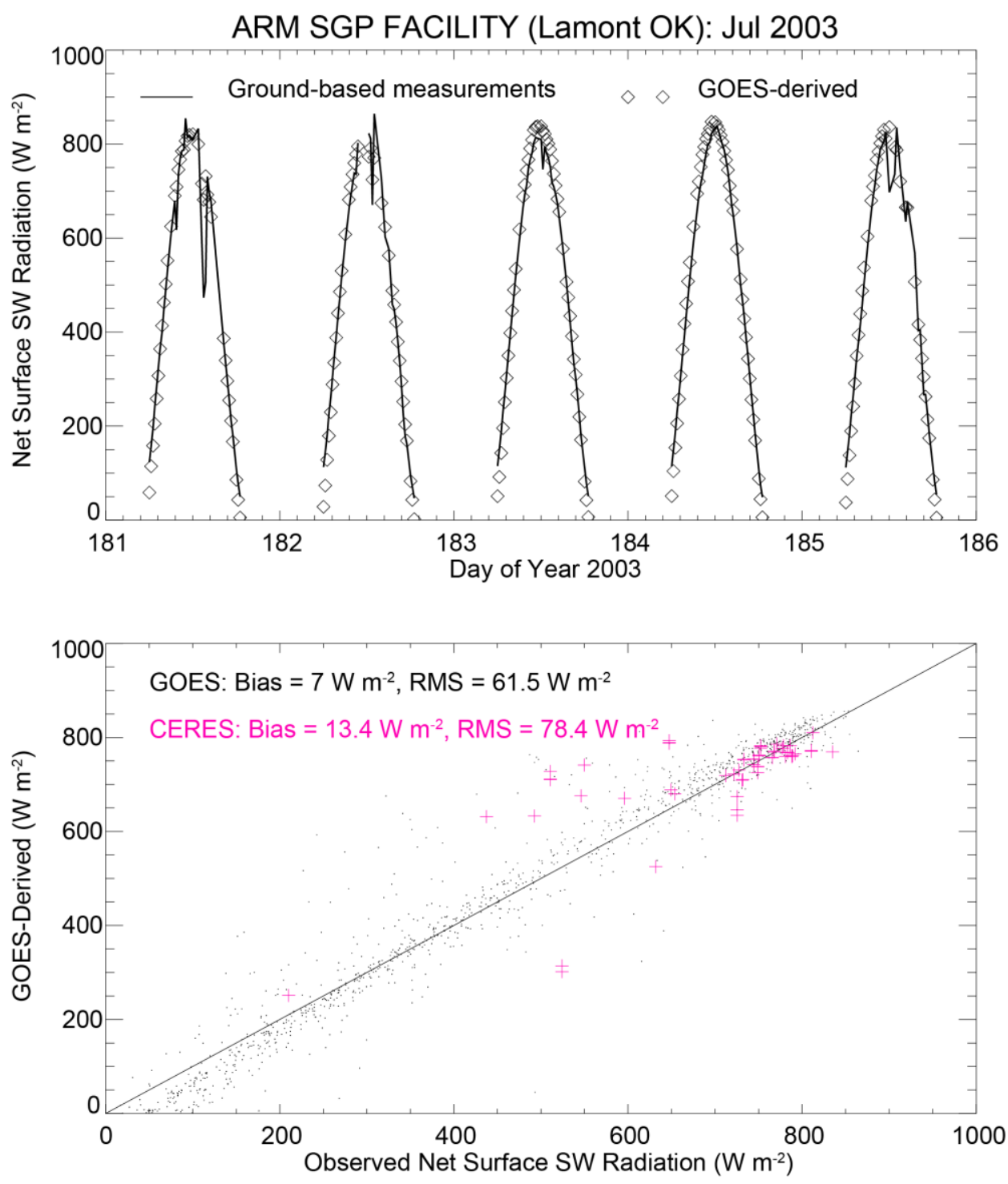

Figure 3. Time series of net surface SW flux measured at ground (continuous solid line) and those retrieved from GOES-10 (green symbols) (top); Scatter plot of matched pairs of observed and modeled values from top panel. Magenta diamond symbols show the comparison with CERES products (bottom).

Results presented in Figures 3 and 4 and Table 3 have been derived using the entire range of solar and view zenith angles. Results shown in the two panels of Figure 4 reveal similar good agreement overall as in Figure 3, albeit with a slightly increased root mean square error, except for the month of January 2003. For most of the stations, we observed a larger bias in January due to the presence of wide-spread snow-cover over many of the station sites associated with larger spatial variability of surface albedo. Although, the overall bias shown for January 2007 is small as compared with January 2003, it is to be noted that it is masked by compensating larger bias values (see Table 3 ) for individual stations. For instance, positive bias values over BOS, BON and PSU sites is compensated by negative bias values over SGP, DRA, FPK, SXF and GCR for January 2007. 
jan03

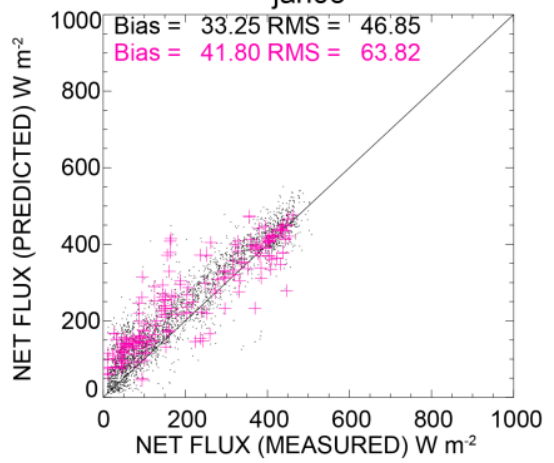

jul03
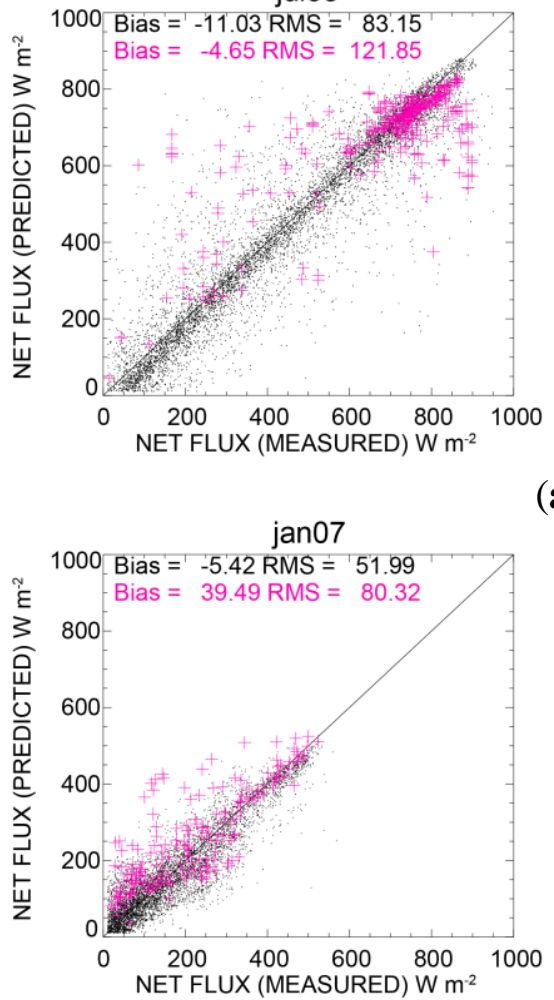

jul07

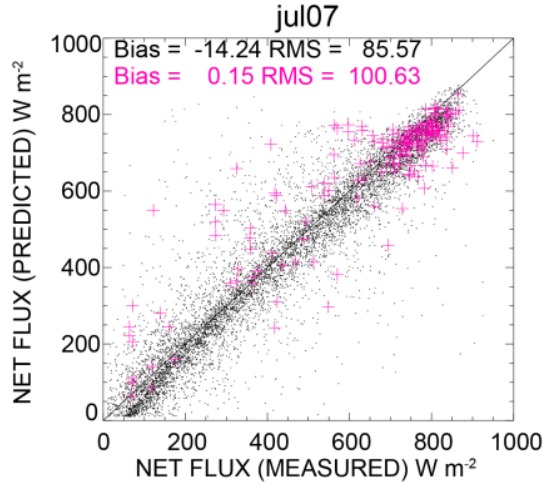

apr03

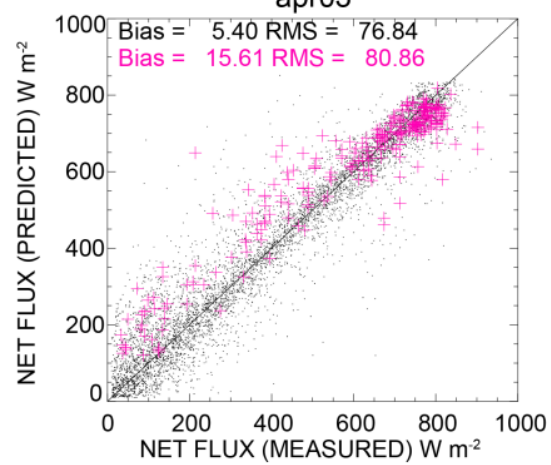

oct03

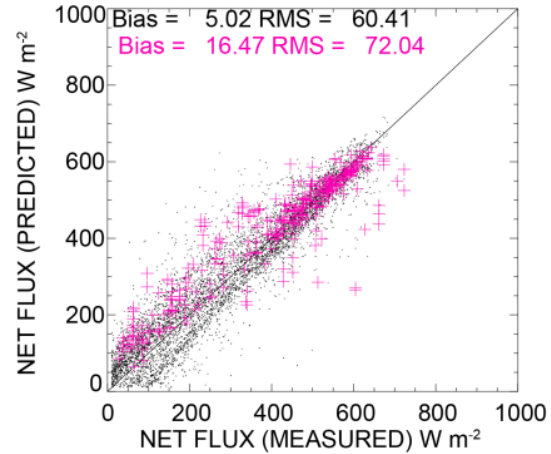

(a)

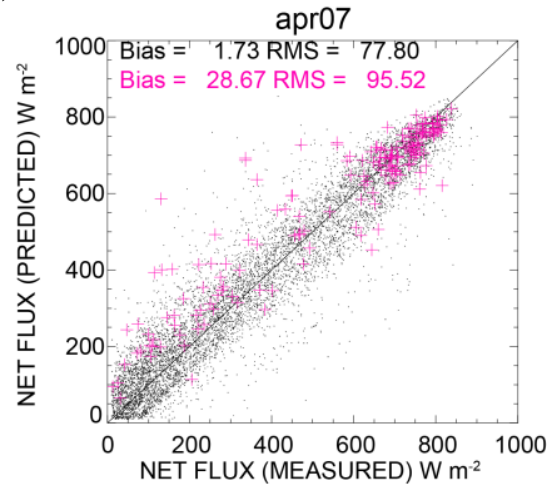

oct07

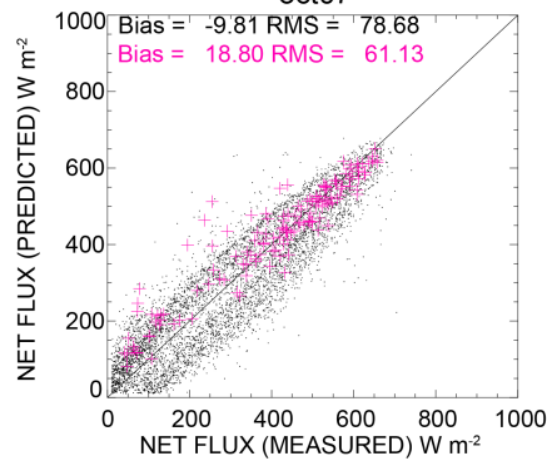

(b)

Figure 4. (a) Scatter plots of observed versus GOES-derived net surface SW flux for all eight SURFRAD stations combined, for the months of January, April, July and October 2003. The black dots refer to the GOES and the magenta symbols represent the CERES Model B. The corresponding bias and RMS numbers inset in the figure are in $\mathrm{W} \cdot \mathrm{m}^{-2}$; (b) Same as in Figure 4a, but for the months of January, April, July and October 2007. 
BOS

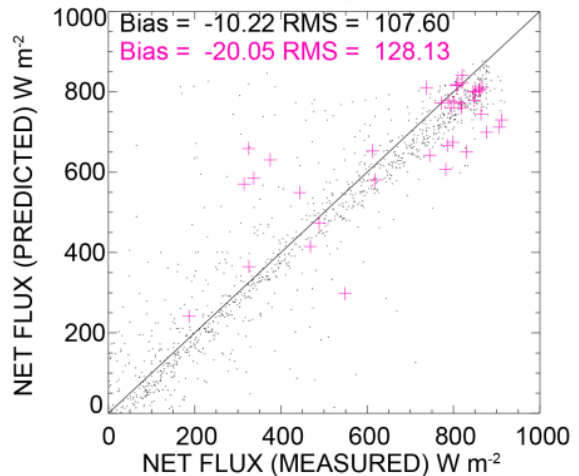

GCR

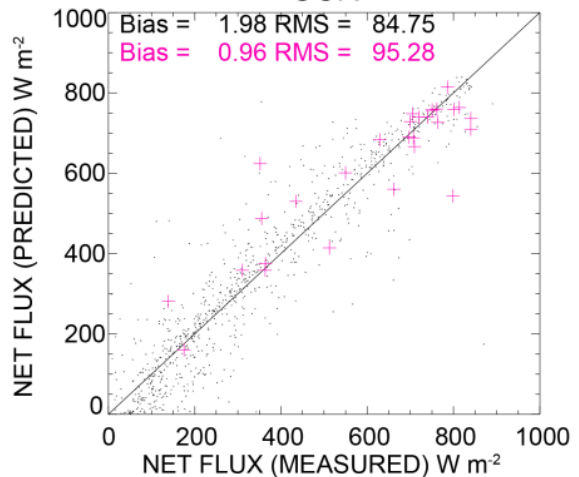

(a)

DRA

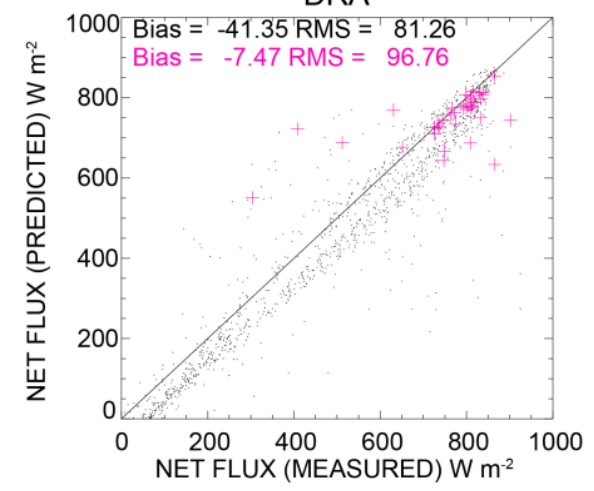

PSU

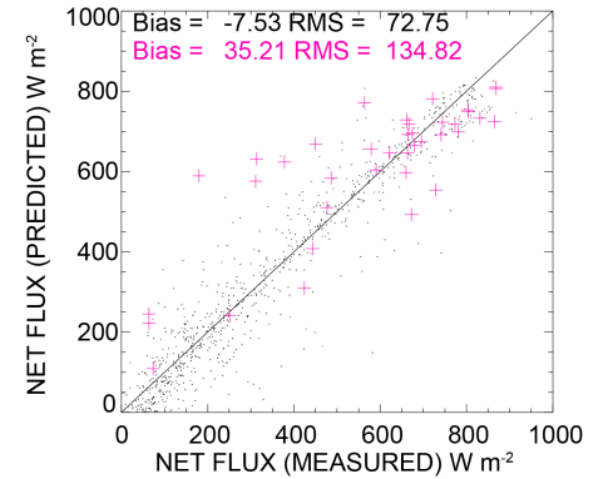

SGP

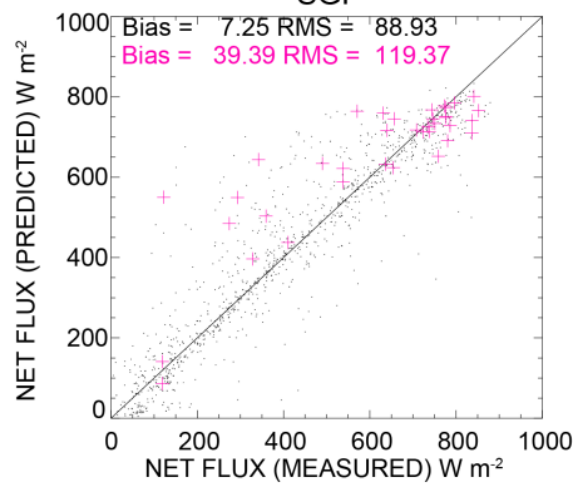

SXF

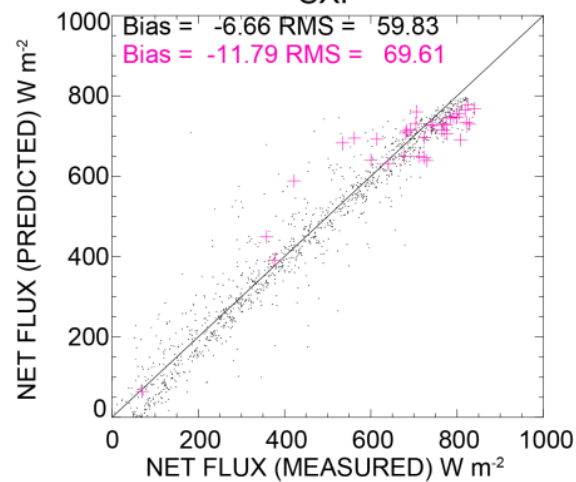

FPK

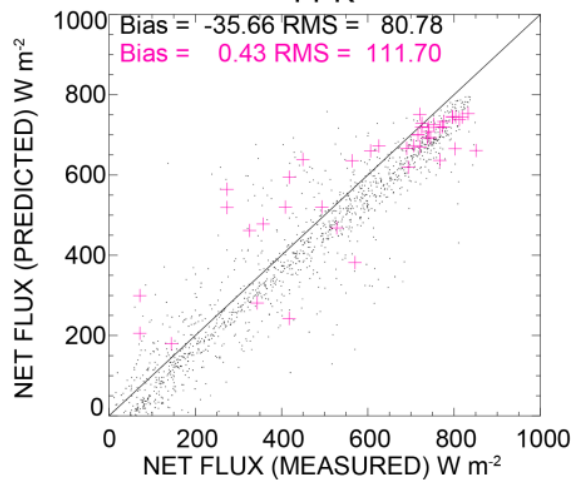

BON

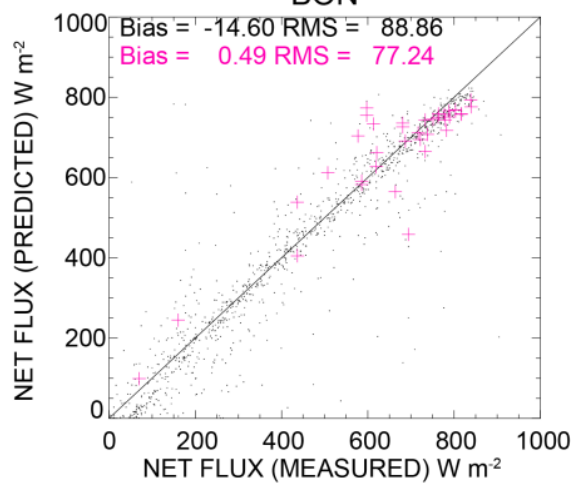

(b)

Figure 5. (a) Scatter plots of measured vs predicted net surface fluxes for the BOS, SGP, GCR and SXF sites for the month of July 2007; (b) Same as Figure 4a, but for the DRA, FPK, PSU and BON sites, showing the effect of larger MISR AODs on the surface net flux. 
Table 3. Summary of error statistics for each station for each month for years 2003 and 2007. Results shown in the first line for each month use the multi-angle imaging spectroradiometer aerosol optical depths (MISR AOD) while those in the second line employs the on-site measurements of multifilter rotating shadowband radiometer (MFRSR) AOD's. There were no on-site measurements for the Southern Great Plains (SGP) site. Mean bias and RMS are in $\mathrm{W} \cdot \mathrm{m}^{-2}$, and the corresponding numbers in parenthesis are percentages.

\begin{tabular}{|c|c|c|c|c|c|c|c|}
\hline & \multirow{2}{*}{ Month } & \multicolumn{2}{|c|}{ GOES } & \multicolumn{2}{|c|}{ CERES Model B } & \multicolumn{2}{|c|}{ AOD } \\
\hline & & Mean Bias & RMS & Mean Bias & RMS & MISR & MFRSR \\
\hline \multirow{7}{*}{ SGP } & Jan03 & $18.3(6.7 \%)$ & $35.5(13 \%)$ & $13.7(4.2 \%)$ & $30.5(9.2 \%)$ & 0.0743 & \\
\hline & Apr03 & $-11.8(-2.8 \%)$ & $52(12 \%)$ & $6.9(1.1 \%)$ & $56(9.3 \%)$ & 0.1744 & \\
\hline & Jul03 & $7(1.5 \%)$ & $61.5(13 \%)$ & $13.4(1.9 \%)$ & $78.4(11 \%)$ & 0.1662 & \\
\hline & Oct03 & $-2(-0.6 \%)$ & $52.5(16 \%)$ & $8.2(1.8 \%)$ & $93(20 \%)$ & 0.0492 & \\
\hline & Jan07 & $-9.4(4.6 \%)$ & $44.9(22.2 \%)$ & $55.5(20 \%)$ & $63.1(22.8 \%)$ & 0.0809 & \\
\hline & Apr07 & $-1.7(-0.4 \%)$ & $66.4(17 \%)$ & $32.5(5.7 \%)$ & $125.4(21.8 \%)$ & 0.0989 & \\
\hline & Jul07 & $7.3(1.7 \%)$ & $88.9(21.3 \%)$ & $39.4(6.5 \%)$ & $119.4(19.7 \%)$ & 0.2267 & \\
\hline \multirow{16}{*}{ DRA } & Jan03 & $33.4(12.3 \%)$ & $35(12.9 \%)$ & $10.2(2.8 \%)$ & $48(13.4 \%)$ & 0.0665 & 0.0313 \\
\hline & & $36.6(13.4 \%)$ & $34.7(12.7 \%)$ & & & & \\
\hline & Apr03 & $0(0 \%)$ & $59.1(12.5 \%)$ & $-42.7(5.7 \%)$ & $62.4(8.3 \%)$ & 0.2075 & 0.0765 \\
\hline & & $15.7(3.3 \%)$ & $58.1(12.3 \%)$ & & & & \\
\hline & Jul03 & $-7(-1.5 \%)$ & $67.4(14.2 \%)$ & $-29(-3.9 \%)$ & $113.6(15.2 \%)$ & 0.1882 & 0.1022 \\
\hline & & $4.3(0.9 \%)$ & $66.8(14.1 \%)$ & & & & \\
\hline & Oct03 & $20.5(5.5 \%)$ & $62.7(16.8 \%)$ & $-16.6(-2.9 \%)$ & $37.3(6.6 \%)$ & 0.1109 & 0.0622 \\
\hline & & $25.7(6.9 \%)$ & $61.1(16.3 \%)$ & & & & \\
\hline & Jan07 & $-21.1(7.1 \%)$ & $41.3(14 \%)$ & $4(1 \%)$ & $46.1(11.3 \%)$ & 0.0621 & 0.0371 \\
\hline & & $-18.5(-6.3 \%)$ & $41.8(14.1 \%)$ & & & & \\
\hline & Apr07 & $-37(-7.9 \%)$ & $81.1(17.3 \%)$ & $-7.9(-1.2 \%)$ & $119.7(17.7 \%)$ & 0.1647 & 0.0829 \\
\hline & & $-25.7(-5.5 \%)$ & $80.9(17.2 \%)$ & & & & \\
\hline & Jul07 & $-41.4(-8.1 \%)$ & $81.3(16 \%)$ & $-7.5(-1 \%)$ & $96.8(12.8 \%)$ & 0.2065 & 0.0906 \\
\hline & & $-24.9(-4.9 \%)$ & $82.3(16.2 \%)$ & & & & \\
\hline & Oct07 & $-23.6(-5.9 \%)$ & $93.3(23.4 \%)$ & $-7.6(-1.4 \%)$ & $45(8.3 \%)$ & 0.0820 & 0.0451 \\
\hline & & $-19.4(-4.9 \%)$ & $92.3(23.3 \%)$ & & & & \\
\hline \multirow{16}{*}{ BOS } & Jan03 & $25.3(10.7 \%)$ & $66.8(28.2 \%)$ & $20.5(7.1 \%)$ & $95(32.8 \%)$ & 0.0388 & 0.0444 \\
\hline & & $24.5(10.4 \%)$ & $66.3(28 \%)$ & & & & \\
\hline & Apr03 & $-0.1(0 \%)$ & $95.9(24.2 \%)$ & $-6.6(-1 \%)$ & $145(23.3 \%)$ & 0.1156 & 0.0686 \\
\hline & & $7.2(1.8 \%)$ & $97.4(24.6 \%)$ & & & & \\
\hline & Jul03 & $-22.8(-5.2 \%)$ & $119(27.1 \%)$ & $-50.2(-7 \%)$ & $167(23.3 \%)$ & 0.1440 & 0.1092 \\
\hline & & $-17.7(4 \%)$ & $119.8(27.2 \%)$ & & & & \\
\hline & Oct03 & $-2.7(-0.8 \%)$ & $75.1(23.3 \%)$ & $24.6(5.5 \%)$ & $85.9(19.3 \%)$ & 0.0441 & 0.0552 \\
\hline & & $-4(-1.2 \%)$ & $74.4(23.1 \%)$ & & & & \\
\hline & Jan07 & $23.6(23 \%)$ & $56.7(55.3 \%)$ & $137(95.5 \%)$ & $84.9(59.3 \%)$ & 0.0489 & 0.0384 \\
\hline & & $24.9(24.3 \%)$ & $56.8(55.3 \%)$ & & & & \\
\hline & Apr07 & $-2.1(-0.5 \%)$ & $98.1(25.5 \%)$ & $13.5(2.5 \%)$ & $173(32.1 \%)$ & 0.1396 & 0.0828 \\
\hline & & $6.6(1.7 \%)$ & $98.6(25.7 \%)$ & & & & \\
\hline & Jul07 & $-0.2(-2.2 \%)$ & $107.7(22.7 \%)$ & $20.1(-2.9 \%)$ & $128(18.3 \%)$ & 0.1423 & 0.1323 \\
\hline & & $-8.7(-1.8 \%)$ & $106.9(22.6 \%)$ & & & & \\
\hline & Oct07 & $-25.3(-7.4 \%)$ & $89.6(26 \%)$ & $-13.6(-2.8 \%)$ & $84.8(17.6 \%)$ & 0.0534 & 0.0461 \\
\hline & & $-24.5(-7.1 \%)$ & $89.2(25.9 \%)$ & & & & \\
\hline
\end{tabular}


Table 3. Cont.

\begin{tabular}{|c|c|c|c|c|c|c|c|}
\hline & \multirow{2}{*}{ Month } & \multicolumn{2}{|c|}{ GOES } & \multicolumn{2}{|c|}{ CERES Model B } & \multicolumn{2}{|c|}{ AOD } \\
\hline & & Mean Bias & RMS & Mean Bias & RMS & MISR & MFRSR \\
\hline \multirow{16}{*}{ BON } & Jan03 & $45.5(38.2 \%)$ & $43.9(36.8 \%)$ & $80.4(58 \%)$ & $58.3(42.1 \%)$ & 0.0860 & 0.0399 \\
\hline & & $51.1(43 \%)$ & $44(37 \%)$ & & & & \\
\hline & Apr03 & $10.8(3.2 \%)$ & $79.7(23.2 \%)$ & $48.8(9.2 \%)$ & $54.4(10.3 \%)$ & 0.2686 & 0.1272 \\
\hline & & $33.6(9.8 \%)$ & $71.3(20.8 \%)$ & & & & \\
\hline & Jul03 & $-32.7(-7 \%)$ & $77.8(16.7 \%)$ & $62(10 \%)$ & $145(23.5 \%)$ & 0.2078 & 0.184 \\
\hline & & $-28.6(-6.1 \%)$ & $78.5(16.8 \%)$ & & & & \\
\hline & Oct03 & $19.4(7.1 \%)$ & $57.38(21.3 \%)$ & $49.1(13.5 \%)$ & $60.2(16.5 \%)$ & 0.0933 & 0.0843 \\
\hline & & $20.7(7.6 \%)$ & $58.1(21.4 \%)$ & & & & \\
\hline & Jan07 & $17.3(13.9 \%)$ & $39.8(31.8 \%)$ & $66.3(36.8 \%)$ & $61.8(34.3 \%)$ & 0.1131 & 0.0865 \\
\hline & & $20.2(16.2 \%)$ & $39.7(31.8 \%)$ & & & & \\
\hline & Apr07 & $31.3(9.7 \%)$ & $51.2(15.9 \%)$ & $61.4(12.8 \%)$ & $76.8(16.1 \%)$ & 0.1713 & 0.1152 \\
\hline & & $39.6(12.3 \%)$ & $50.9(15.8 \%)$ & & & & \\
\hline & Jul07 & $-14.6(-3.2 \%)$ & $88.9(19.5 \%)$ & $0.5(0 \%)$ & $77.2(11 \%)$ & 0.2758 & 0.1217 \\
\hline & & $4.4(1 \%)$ & $78.3(17.2 \%)$ & & & & \\
\hline & Oct07 & $9.8(4.3 \%)$ & $66.6(29.1 \%)$ & $74.4(23.2 \%)$ & $78.3(24.4 \%)$ & 0.1168 & 0.0727 \\
\hline & & $15.2(6.6 \%)$ & $65.6(28.7 \%)$ & & & & \\
\hline \multirow{16}{*}{ FPK } & Jan03 & $21(22.4 \%)$ & $36.8(39.3 \%)$ & $38(34.3 \%)$ & $56.2(50.7 \%)$ & 0.0584 & 0.022 \\
\hline & & $24.9(26.6 \%)$ & $38.1(40.6 \%)$ & & & & \\
\hline & Apr03 & $19.1(6.1 \%)$ & $83.5(26.7 \%)$ & $55.3(12.3 \%)$ & $96.5(21.5 \%)$ & 0.1612 & 0.1025 \\
\hline & & $27.5(8.8 \%)$ & $77(24.6 \%)$ & & & & \\
\hline & Jul03 & $1.5(0.4 \%)$ & $65.8(15.6 \%)$ & $0.3(0 \%)$ & $83.2(12.4 \%)$ & 0.1471 & 0.0804 \\
\hline & & $10.2(2.4 \%)$ & $65.7(15.5 \%)$ & & & & \\
\hline & Oct03 & $-4.7(-2.1 \%)$ & $50.2(22.7 \%)$ & $25.9(8.6 \%)$ & $56.2(18.8 \%)$ & 0.0610 & 0.036 \\
\hline & & $-2(-0.9 \%)$ & $49.7(22.4 \%)$ & & & & \\
\hline & Jan07 & $-23.6(-16.6 \%)$ & $30.6(27.2 \%)$ & $-32.2(-16.6 \%)$ & $64.5(33.3 \%)$ & 0.0602 & 0.0275 \\
\hline & & $-20.8(-14.7 \%)$ & $37.9(26.7 \%)$ & & & & \\
\hline & Apr07 & $-16.8(-4.63 \%)$ & $78.7(21.6 \%)$ & $-13.6(-2.5 \%)$ & $86.5(15.8 \%)$ & 0.1418 & 0.0893 \\
\hline & & $-10(-2.7 \%)$ & $78.5(21.6 \%)$ & & & & \\
\hline & Jul07 & $-35.6(-8.1 \%)$ & $80.7(18.3 \%)$ & $-0.4(0 \%)$ & $112(18.4 \%)$ & 0.2405 & 0.1363 \\
\hline & & $-21(-4.8 \%)$ & $76.8(17.4 \%)$ & & & & \\
\hline & Oct07 & $-26.9(-11.3 \%)$ & $71.7(30.3 \%)$ & $5.1(1.4 \%)$ & $58.5(16.3 \%)$ & 0.0820 & 0.0383 \\
\hline & & $-22.1(-9.3 \%)$ & $72.1(30.5 \%)$ & & & & \\
\hline \multirow{12}{*}{ SXF } & Jul03 & $-17.6(-4 \%)$ & $75.1(16.9 \%)$ & $21.1(3.5 \%)$ & $102.1(17.1 \%)$ & 0.1493 & 0.2634 \\
\hline & & $-34.2(-7.7 \%)$ & $76.9(17.3 \%)$ & & & & \\
\hline & Oct03 & $-3.4(-1.4 \%)$ & $48.7(19.5 \%)$ & $30.9(9.1 \%)$ & $59.1(17.4 \%)$ & 0.0712 & 0.0478 \\
\hline & & $-0.5(-0.2 \%)$ & $48.1(19.3 \%)$ & & & & \\
\hline & Jan07 & $-37.1(-22.9 \%)$ & $60.9(37.6 \%)$ & $-5.4(-2.5 \%)$ & $52.9(23.8 \%)$ & 0.0471 & 0.0391 \\
\hline & & $-36.6(-22.6 \%)$ & $61.5(37.9 \%)$ & & & & \\
\hline & Apr07 & $-19.5(-5 \%)$ & $77.7(19.9 \%)$ & $20.7(4 \%)$ & $69.6(13.4 \%)$ & 0.1651 & 0.1259 \\
\hline & & $-8.1(-2.1 \%)$ & $74.4(19.1 \%)$ & & & & \\
\hline & Jul07 & $-6.3(-1.4 \%)$ & $59.9(13.2 \%)$ & $-11.8(-1.7 \%)$ & $69.6(10.2 \%)$ & 0.1063 & 0.1479 \\
\hline & & $-12.2(-2.7 \%)$ & $59(13 \%)$ & & & & \\
\hline & Oct07 & $-5.7(-2.3 \%)$ & $70.6(27.9 \%)$ & $19.4(5.2 \%)$ & $53.3(14.2 \%)$ & 0.0555 & 0.0589 \\
\hline & & $-6.2(-2.5 \%)$ & $70.7(28 \%)$ & & & & \\
\hline
\end{tabular}


Table 3. Cont.

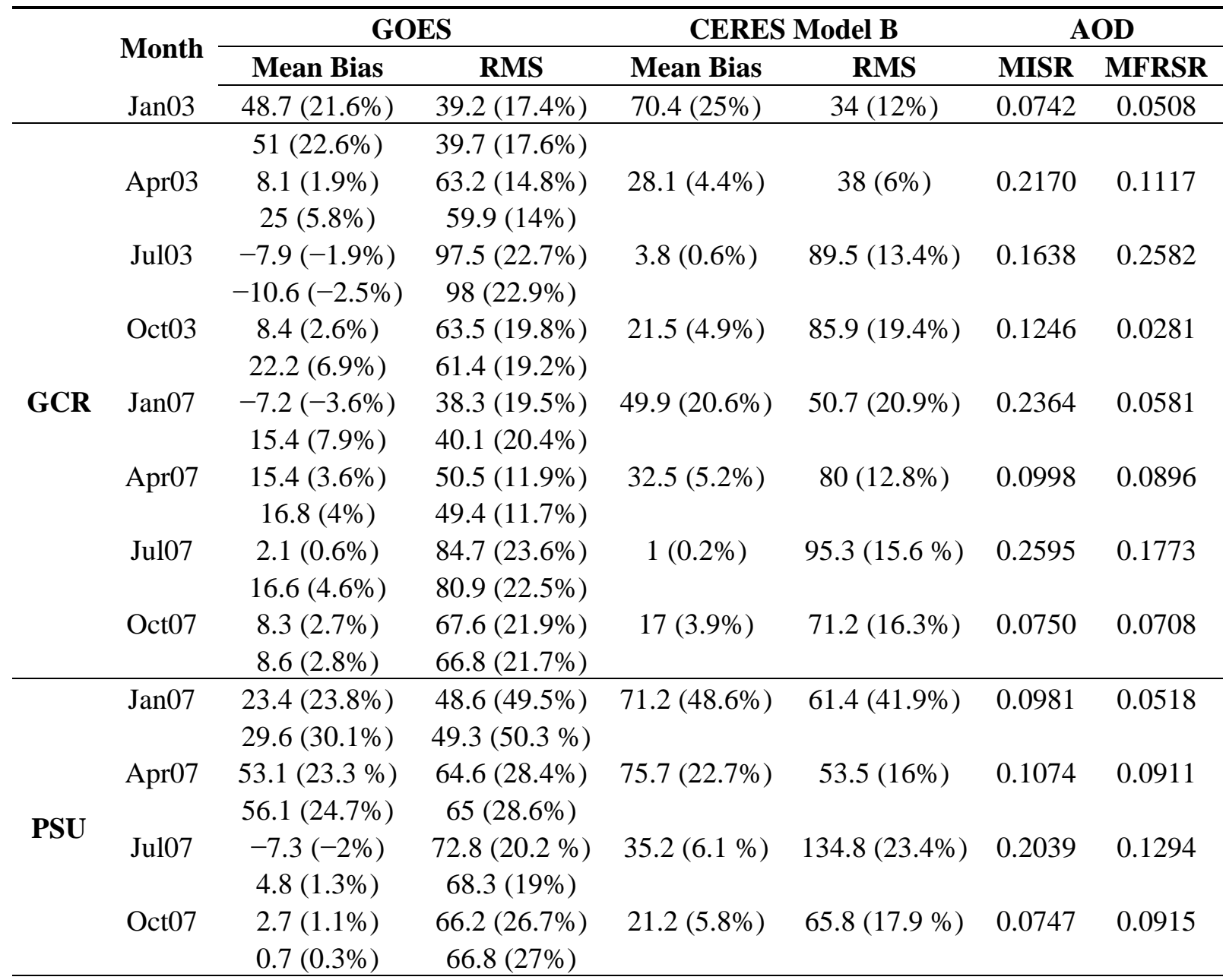

The negative bias observed in July (both in 2003 and 2007) (Figure 4) is partially due to an overestimation of aerosol optical depths retrieved from MISR during these months resulting in an increased atmospheric absorption. For example, the MISR AOD values during July (see Table 3) for DRA, FPK, BON and PSU in July 2007 are higher than ground-based AOD measurements by around 0.15 and 0.2 , resulting in an average excess absorption of around $30 \mathrm{~W} \cdot \mathrm{m}^{-2}$. Validation results are represented by the mean bias, RMS (relative deviations from ground-based measurements are in parenthesis) between ground-based and GOES and CERES derived products. With a higher spatial resolution (1 $\mathrm{km}$ at nadir) closer to the station spatial representativeness than CERES, the GOES-retrieved products are globally in better agreement with the ground-based measurements than CERES derived products. Furthermore, the center of CERES FOV may be as much as $20 \mathrm{~km}$ away from the ground site point measurement. However, for the present study, only CERES pixels with centers less than $10 \mathrm{~km}$ away from the ground site have been chosen for the validation. Therefore, the observed differences between GOES and CERES products are mainly due to spatial variability of surface albedo and incoming radiation. The effect of surface albedo spatial variability on net surface SW radiation will be discussed later. Moreover, we observed a persistent positive bias in the CERES results that is mainly due to the presence of clouds, i.e., the spatial variability within cloud fields often produces conditions where 1-min averaging of surface measurements cannot represent surface conditions over the larger 20-km CERES footprint [29]. It is evident from Figures 4-5 that CERES net fluxes have a pattern of 
negative bias for clear-sky conditions (as represented by higher values of net flux) and a positive bias for cloudy skies which is consistent with results posted in Table 1 of [29] for continents.

For most of the sites, two different aerosol optical depth products (at $0.55 \mu \mathrm{m}$ ) have been used and the impact on validation results is presented in Table 3. The first AOD product is from MISR on-board Terra and the second AOD products is derived from ground-based measurements (MFRSR instrument available at seven sites - no measurements available for the SGP site near Lamont). The time-series of AOD values for each station follow the reported US climatology of aerosols [30], with maximum values in summer (July) and minimum values in the winter (January), and the maximum variability of aerosols occurs during the summer months. Results derived from the MFRSR AOD's are shown in the second line for each month except the SGP. The CERES sub-system uses a proprietary scheme of aerosol assimilation based on a combination of satellite and a model of atmospheric transport and chemistry [31]. The aerosols from the MFRSR instrument have been validated against the AERONET measurements and claimed to be accurate. Globally, monthly averages of MISR aerosol measurements are in good agreement with monthly average of MFRSR AOD (Table 3). At a higher temporal resolution, differences are more significant and can be due to data pre-processing, such as gap-filling technique used for MISR based on linear interpolations. Differences between both aerosol products partly explain observed significant biases between the field and satellite retrievals (Table 3). For instance, MISR-retrieved aerosol optical depths are significantly higher than MFRSR measurements at Desert Rock, NV (DRA), which is a semi-arid area. The differences are related to the increased difficulty of retrieving aerosol products over bright surfaces. Using AOD products from ground measurements has been found to drop the bias values by more than 50\% at Desert Rock, NV. Overall we find larger biases (e.g., in July for most of the sites) are associated with significant differences between satellite-derived and ground-based AOD values (Figure 5, Table 3). This is illustrated in Figure 5a,b, which show scatter plots of ground-measured and model-predicted net surface fluxes for all stations for the month of July 2007. For the SGP, BOS, SXF and GCR sites (Figure 5a), where the two AOD values agree closely, the mean values of bias are about 3\%. Stations with significant differences in AOD are shown in Figure 5b, with the DRA and FPK sites displaying larger bias. It needs to be emphasized here, that while significantly over or under-estimated AOD's can enhance the bias, not all of the observed bias can be attributed to the measured AOD. Although the downward SW radiation is spatially more uniformly distributed at least over flatter terrains, the net surface radiation is more influenced by the surface broadband albedo. Indeed, the Landsat Enhanced Thematic Mapper Plus (ETM+) data [32] have shown that the land cover around BON, GCR, SXF and PSU sites to be spatially complex and heterogeneous during both the periods of vegetation dormancy and snow-cover. Also, evaluation of the daily downward shortwave radiation from the latest FLASHFlux/CERES (Fast Longwave and Shortwave Fluxes_Time Interpolated and Spatially Averaged/CERES) satellite product [33] with in situ data over rugged terrains such as the Tibetan Plateau has revealed mean absolute errors of about $12 \%$.

Error statistics from some of the other reported studies cited in the beginning section, on incident surface SW radiation are presented in Table 4 for comparison. The temporal and spatial resolution along with mean bias and RMS deviation are shown in different columns. Mean bias errors range from about $2 \%-6 \%$, while the RMS values range from $18 \%$ to $35 \%$ for all-sky conditions. The numbers for the simplified GEWEX model [17] in row 4 are for seasonally-averaged periods. 
Table 4. Summary of error statistics for downward SW flux derived from other studies. The data set name and its source are indicated in the first column.

\begin{tabular}{|c|c|c|c|c|}
\hline Data Set Description & Temporal Interval & Spatial Interval & Mean Bias in $\mathrm{W} \cdot \mathrm{m}^{-2}$ & RMS in $\mathrm{W} \cdot \mathrm{m}^{-2}$ \\
\hline GEWEX-SRB [16] & $3 \mathrm{~h}$ & $1^{\circ}$ lat-lon & $-5.5(-1.9 \%)$ & $101.3(35 \%)$ \\
\hline ISCCP-FD [15] & $3 \mathrm{~h}$ & $280 \mathrm{~km}$ & $2.8(0.3 \%)$ & $101.7(35 \%)$ \\
\hline CERES-FSW [2] & $1 \mathrm{~h}$ & $25 \mathrm{~km}$ & $29.7(6 \%)$ & $123.2(25 \%)$ \\
\hline Simplified GEWEX [17] & $\begin{array}{c}1 \mathrm{~h} \\
\text { (seasonally averaged) }\end{array}$ & $1^{\circ}$ lat-lon & $-2(\mathrm{~N} / \mathrm{A})$ & $62(19 \%)$ \\
\hline \multicolumn{5}{|l|}{ CERES Model B [29] } \\
\hline Clear Sky & $1 \mathrm{~min}$ & $20 \mathrm{~km}$ & -21 to $-24(-3.6 \%)$ & $28(4 \%)$ \\
\hline Cloudy Sky & $1 \mathrm{~h}$ & $20 \mathrm{~km}$ & $27-31(6 \%)$ & $90(18 \%)$ \\
\hline
\end{tabular}

In summary, the performance of the proposed algorithm to derive GOES imager-based estimates of net surface SW flux is comparable and in many cases even better than other reported results including those produced by the CERES sub-systems.

\subsection{Spatial Representativeness of Ground-Based Measurements}

To evaluate the performance of the surface net SW radiation algorithm developed for GOES, we considered that the area surrounding a ground station (around $1.5 \times 1.5 \mathrm{~km}^{2}$ for GOES for instance) is relatively homogeneous in terms of land cover types and biophysical parameters, e.g., surface albedo and vegetation density, and we assume that scaling effects are insignificant and can be neglected at moderate resolution. This hypothesis is used to compare ground-based and GOES-derived products irrespective of the spatial resolution. To verify such a hypothesis and quantify the level of heterogeneity of each validation site, we use standard surface albedo and NDVI products from MODIS with a spatial resolution of $500 \mathrm{~m}$ for the albedo and $250 \mathrm{~m}$ for the NDVI products, respectively. The spatial variability of surface albedo directly affects the scaling of surface SW net radiation products and is used to assess the spatial representativeness of the ground-based measurements used in this study, while spatial variability of NDVI may affect the quality of the GOES-derived TOA broadband SW radiation. Only good quality MODIS products available in 2003 and 2007 are considered. We estimate the albedo and NDVI at various moderate resolution pixel sizes by aggregating MODIS gridded pixels over a range of $1.5 \mathrm{~km}$ (for GOES) to $10 \mathrm{~km}$ (for CERES footprint center area) centered on the station location (Table 4). Results show that changes in spatial resolution do not significantly affect both surface albedo and NDVI around each of the selected SURFRAD stations. The differences observed between MODIS products aggregated at $\sim 1.5 \mathrm{~km}$ spatial resolution-average of $3 \times 3$ pixels for the albedo and $6 \times 6$ pixels for the NDVI- and the value of the pixel containing the station are not significant and usually lower than $2 \%$ in relative (Table 5). The differences are slightly higher and around $4 \%$ on average when considering coarser resolution, i.e., $\sim 10 \mathrm{~km}$ that represents an approximation of the main contributive area in the CERES footprint, and up to 15\% for Fort Peck in April, and 19\% for Penn State University in April. Such differences clearly explain why GOES-derived surface net SW radiation products with a higher spatial resolution than CERES-based products are usually in better agreement with ground-based measurements than CERES. The land surface surrounding each SURFRAD station and within a GOES pixel is relatively homogeneous in terms of albedo, and the observed spatial variability of albedo does not significantly affect validation results of GOES-retrieved SW net radiation. 
It is usually not the case for CERES, for which higher relative differences with ground-based measurements are observed over heterogeneous sites in terms of surface albedo, e.g., Penn State University and Fort peck, and low discrepancies with the stations are observed for more homogeneous sites, e.g., Desert Rock, ARM Great Plains.

Table 5. Mean and standard deviation (STD) of MODIS-derived albedo (native spatial resolution of $500 \mathrm{~m}$ ) and NDVI (native resolution of $250 \mathrm{~m}$ ) values aggregated over various spatial areas centered on SURFRAD validation sites located in Bondville, IL (BON), Table Mountain, CO (BOS), Desert Rock, NV (DRA), Lamont, OK (SGP), Fort Peck, MT (FPK), Goodwin Creek, MS (GCR), Penn State, PA (PSU) and Sioux Fall, SD (SXF). The spatial resolution varies from one pixel that includes the station to $\sim 1.5 \mathrm{~km}$ and $\sim 10 \mathrm{~km}$. Reported values are for 2003 — similar results were found for 2007.

\begin{tabular}{|c|c|c|c|c|c|c|c|c|c|}
\hline \multirow{3}{*}{ Site } & \multirow{3}{*}{ Resolution } & \multicolumn{4}{|c|}{ Albedo } & \multicolumn{4}{|c|}{ NDVI } \\
\hline & & \multicolumn{2}{|c|}{ April } & \multicolumn{2}{|c|}{ July } & \multicolumn{2}{|c|}{ April } & \multicolumn{2}{|c|}{ July } \\
\hline & & Mean & STD & Mean & STD & Mean & STD & Mean & STD \\
\hline \multirow{3}{*}{$\mathrm{BON}$} & Station & 0.152 & - & 0.174 & - & 0.44 & - & 0.795 & - \\
\hline & $\sim 1.5 \mathrm{~km}$ & 0.150 & 0.003 & 0.179 & 0.006 & 0.298 & 0.047 & 0.856 & 0.047 \\
\hline & $\sim 10 \mathrm{~km}$ & 0.148 & 0.006 & 0.185 & 0.007 & 0.298 & 0.048 & 0.881 & 0.039 \\
\hline \multirow{3}{*}{ BOS } & Station & 0.155 & - & 0.151 & - & 0.382 & - & 0.354 & - \\
\hline & $\sim 1.5 \mathrm{~km}$ & 0.156 & 0.007 & 0.154 & 0.008 & 0.389 & 0.057 & 0.437 & 0.137 \\
\hline & $\sim 10 \mathrm{~km}$ & 0.150 & 0.02 & 0.147 & 0.025 & 0.403 & 0.097 & 0.483 & 0.114 \\
\hline \multirow{3}{*}{ DRA } & Station & 0.186 & - & 0.186 & - & 0.186 & - & 0.120 & - \\
\hline & $\sim 1.5 \mathrm{~km}$ & 0.188 & 0.010 & 0.186 & 0.010 & 0.170 & 0.021 & 0.125 & 0.009 \\
\hline & $\sim 10 \mathrm{~km}$ & 0.190 & 0.018 & 0.188 & 0.021 & 0.174 & 0.023 & 0.131 & 0.009 \\
\hline \multirow{3}{*}{ SGP } & Station & 0.163 & - & 0.173 & - & 0.644 & - & 0.508 & - \\
\hline & $\sim 1.5 \mathrm{~km}$ & 0.165 & 0.003 & 0.173 & 0.003 & 0.668 & 0.010 & 0.494 & 0.073 \\
\hline & $\sim 10 \mathrm{~km}$ & 0.166 & 0.006 & 0.172 & 0.007 & 0.734 & 0.125 & 0.414 & 0.114 \\
\hline \multirow{3}{*}{ FPK } & Station & 0.131 & - & 0.138 & - & 0.303 & - & 0.471 & - \\
\hline & $\sim 1.5 \mathrm{~km}$ & 0.135 & 0.008 & 0.139 & 0.003 & 0.282 & 0.036 & 0.540 & 0.500 \\
\hline & $\sim 10 \mathrm{~km}$ & 0.151 & 0.012 & 0.150 & 0.011 & 0.237 & 0.037 & 0.554 & 0.114 \\
\hline \multirow{3}{*}{ GCR } & Station & 0.148 & - & 0.135 & - & 0.593 & - & 0.805 & - \\
\hline & $\sim 1.5 \mathrm{~km}$ & 0.149 & 0.001 & 0.137 & 0.003 & 0.683 & 0.062 & 0.819 & 0.035 \\
\hline & $\sim 10 \mathrm{~km}$ & 0.146 & 0.005 & 0.145 & 0.01 & 0.721 & 0.072 & 0.816 & 0.060 \\
\hline \multirow{3}{*}{ PSU } & Station & 0.160 & - & 0.158 & - & 0.380 & - & 0.795 & - \\
\hline & $\sim 1.5 \mathrm{~km}$ & 0.150 & 0.016 & 0.154 & 0.007 & 0.440 & 0.078 & 0.774 & 0.069 \\
\hline & $\sim 10 \mathrm{~km}$ & 0.130 & 0.017 & 0.152 & 0.012 & 0.484 & 0.070 & 0.881 & 0.068 \\
\hline \multirow{3}{*}{ SXF } & Station & 0.155 & - & 0.164 & - & 0.343 & - & 0.479 & - \\
\hline & $\sim 1.5 \mathrm{~km}$ & 0.156 & 0.002 & 0.169 & 0.007 & 0.303 & 0.061 & 0.726 & 0.110 \\
\hline & $\sim 10 \mathrm{~km}$ & 0.156 & 0.005 & 0.179 & 0.007 & 0.282 & 0.069 & 0.842 & 0.065 \\
\hline
\end{tabular}

The spatial variability of NDVI around the stations is usually more significant and relative differences between a single pixel and a $6 \times 6$-pixel aggregate of around 20\%, 32\% and 50\% are observed at Table Mountain, CO in July, Bondville, IL in April and Sioux Falls, SD in July, respectively. The large difference between NDVI values at $250 \mathrm{~m}$ and $1.5 \mathrm{~km}$ resolution observed at Sioux Falls is due to the presence of a large building (the USGS-Eros center) near the station. The performance of the validation process is reduced for mixed pixels, and such NDVI spatial variability may partly explain the observed 
discrepancies between the satellite products at coarse resolution and ground reference. The inadequate spatial representativeness of point-scale measurements within the satellite footprint has already been found to significantly degrade validation results [34-36].

Therefore, the algorithm performance slightly varies from site to site, and better validation results are usually observed for homogeneous sites in term of NDVI, e.g., DRA site, with root mean square error between ground-based and satellite-derived SW net radiation less than $15 \%$. Indeed at Desert Rock, the area around the station (around $10 \mathrm{~km} \times 10 \mathrm{~km}$ ) is homogeneous in terms of land cover type, i.e., bare soil. In contrast, the station in Table Mountain (BOS) is located in a very heterogeneous area [35], and differences of around $25 \%$ are observed between ground and satellite-retrieved SW net radiation (Table 4). Actually, for most vegetated landscapes composed of various land cover types or soils, the net SW radiation measured by a station at one specific location-i.e., around a $100 \mathrm{~m} \times 100 \mathrm{~m}$ footprint for SURFRAD - does not represent the surrounding area that is part of the coarser satellite sensor pixel. Authors in $[35,36]$ have shown similar results when evaluating the effect of spatial variability in land cover types and vegetation density on satellite Land Surface Temperature (LST) products using ground-based measurements from the SURFRAD stations. Also, authors in [34] have shown that increasing the number of stations in a satellite field of view significantly increases the spatial representativeness of ground reference.

\subsection{Error Analysis}

Overall accuracy of the parameterization has been assessed through performing a comprehensive comparison of algorithm results and surface observations spanning a wide range of geographical, atmospheric, cloud and surface conditions. So the uncertainties related to these are already factored into the rms errors reported in Table 3. This section presents relative sensitivity of the results of the parameterization to uncertainties in individual input parameters. The main input variables in the parameterization Equation (2) are the TOA SW flux, column water vapor amount, solar zenith angle and aerosol optical depth at $550 \mathrm{~nm}$.

The solar zenith angle is well-defined and available for prescribed geo-location and time of day. Sensitivity of the parameterization to precipitable water vapor, different cloud types, and haze has been performed by [23] and we independently confirm those results here. However, since the study [23] assessed errors from detailed radiative transfer calculations, the sensitivity to the TOA flux in Equation (2) has not been done. Use of satellite-based TOA SW flux is the major contributor to the uncertainty. Since satellite sensors (including CERES) measure only radiance, conversion of this radiance to flux is accomplished through angular dependent models [22]. Earth scenes have distinct anisotropic characteristics which depend on their physical and optical properties such as thin versus thick clouds, overlapping and broken clouds, cloud-free, nature of the underlying surface, etc. Results for CERES ADMs [22] report errors in radiance to flux conversion ranging from 5\% to 7\%. The TOA flux values derived from narrowband to broadband conversion such as that performed here add an additional level of uncertainty. However, studies [37] have shown that errors can be reduced significantly through narrowband to broadband pixel matching, scene selection and homogeneity screening. The present study considers only land scenes, and the homogeneity screening is accomplished through reducing the dispersion of the radiance as described in Section 3.1. We have introduced further stratification in the 
scene selection through using different NDVI intervals. Further instead of adding multiple levels of uncertainty through two-step conversion of detector-measured raw counts to radiance, followed by use of appropriate ADMs to convert from radiance to flux, it was found that using a direct approach of counts to TOA SW flux works well without contributing significantly to the errors. The standard errors in the correlation of the aggregated GOES raw counts (Equation (1), Figure 2, Table 2) and CERES-measured instantaneous TOA SW flux ranged between $6 \%$ and $12 \%$. The larger errors occur for lower values of TOA flux or under less cloudy conditions. Although these errors have been already factored into the rms errors depicted in Table 3, we present below (Figure 6), sensitivity of the net surface SW flux to a $\pm 10 \%$ change (about 1 standard deviation) in the TOA flux, for January, April, July and October of year 2003 for all stations combined. The upper and lower bounds, shown by the blue lines in Figure 6 correspond to $-10 \%$ and $+10 \%$ change in the TOA flux respectively. The pattern of mean errors shown are consistent with results shown Figure 4a. Results for year 2007 are similar.
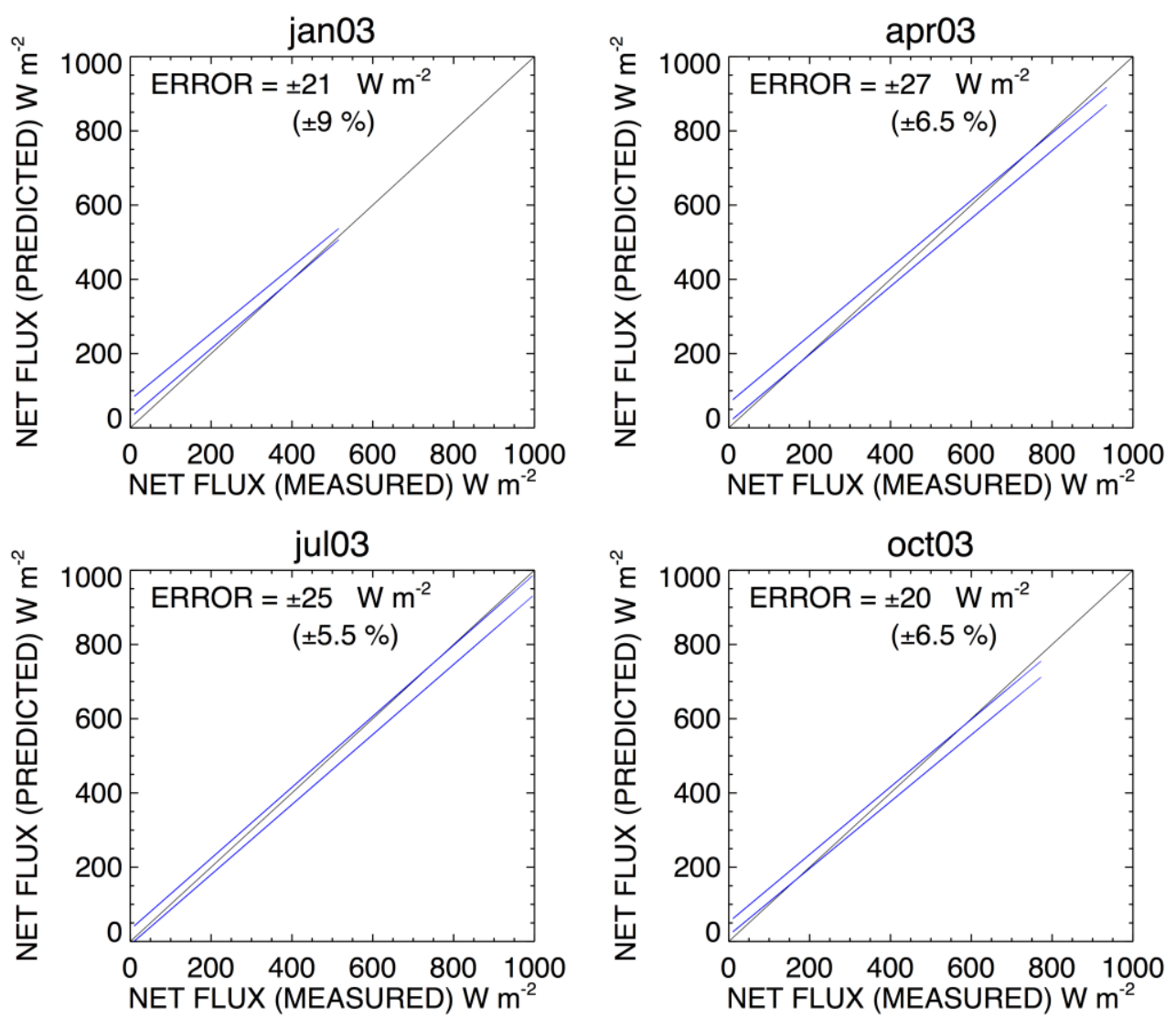

Figure 6. Sensitivity of net surface SW flux to TOA SW flux $( \pm 1 \sigma)$ The blue lines show the bounds, with the lower bound corresponding to +1 standard deviation change in the TOA flux and vice versa. The mean error and percentage are shown in the figure.

In order to determine sensitivity to aerosols, we compare the MISR AODs with on-site measured MFRSR AOD for all stations (except the SGP site), for all months of years 2003 and 2007. Figure 7 shows the histogram distribution of differences in AOD (MISR-MFRSR). The mean bias in MISR AOD is about 0.039 with an rms value of 0.09 . The MFRSR AOD values, which have been validated against AERONET measurements [30] have been used as the benchmark here. Performing sensitivity 
analysis similar to the case of TOA flux described above, impact of imposing a \pm 0.09 change in AOD, which corresponds to 1 standard deviation, results in a change of about $3 \%$ in the derived net surface SW flux.

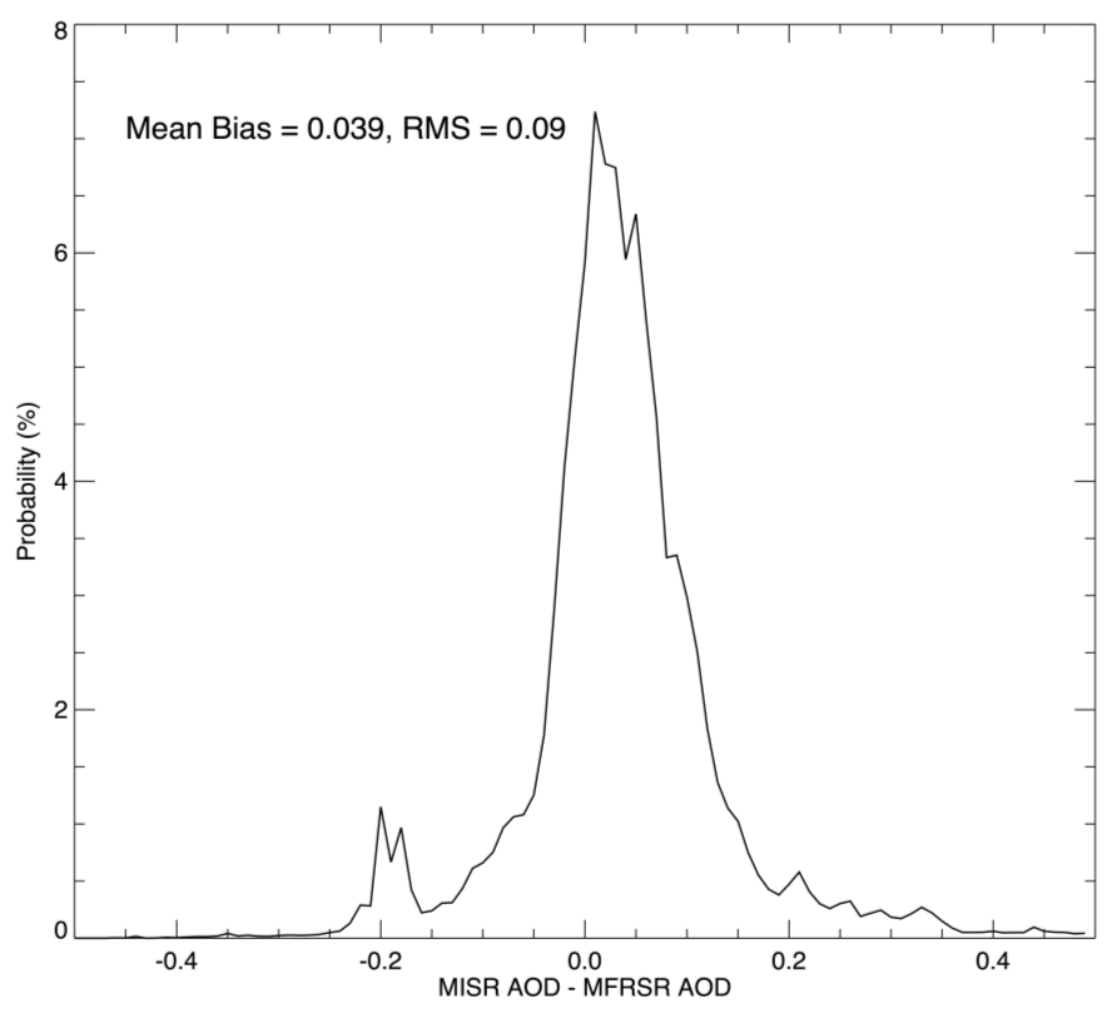

Figure 7. Histogram of AOD difference between MISR and MFRSR for all months of 2003 and 2007, except the SGP site.

The parameterization has been found to be not overly sensitive to the precipitable water amounts retrieved from the MOD05 product. The accuracy of the MODIS water vapor product [38] is between $5 \%-12 \%$. Errors in column water vapor amounts have been found to introduce overall errors of less than $1 \%$ in the net surface flux, which is consistent with the other studies $[23,38]$. An additional factor contributing to the uncertainty is the spatial inhomogeneity in surface broadband albedo which has been discussed in the previous Sections 4.2 and 4.3. However its impact is more pronounced in the CERES retrieval due to the larger size of the footprint.

\section{Conclusions}

Natural and man-made climate forcings such as aerosols, deforestation and rising concentration of greenhouse gases affect the Earth's radiative equilibrium. A relevant quantity for climate modeling and especially for land surface models is the net radiative flux at the surface. The net surface SW radiation forms a key component of the surface energy balance. Even the recently augmented vast network of surface stations [3-5] is inadequate in providing a global coverage of the Earth's surface radiation balance, which includes all representative climate regimes. The study presented here to retrieve the net surface radiation over the continental US region partially fulfills such a need. Also it can be easily extended to other meteorological satellites around the globe and provide data sets that 
support predictions of global and regional climate change, and studies such as GEWEX-related [16] radiation research.

In this paper, we present and evaluate a methodology to derive instantaneous surface net radiation in the SW domain at half-hourly temporal and $1 \mathrm{~km}$ spatial resolution using visible imagery from Geostationary Operational Environmental Satellite (GOES). The retrieval algorithm represents an adaptation to GOES data of a standard algorithm initially developed for CERES. TOA broadband SW radiation estimates have been retrieved from GOES visible band using a linear relationship depending on surface vegetation density - here MODIS NDVI has been used as proxy. The GOES visible imagery has been found to be very well correlated with CERES-retrieved SW TOA radiative flux and matching of the collocated imageries provides the calibration design of the narrow band to broadband relationship. The scheme does not require knowledge of cloud structure or cloud optical properties, but needs additional ancillary input parameters such as the column water vapor amount and the aerosol optical depth at $550 \mathrm{~nm}$.

Comparisons between ground-based measurements from NOAA's SURFRAD observation network and GOES-derived surface net SW radiation have shown good agreements between ground-based and satellite-derived products. Comparisons for all 8 SURFRAD stations for the months of January, April, July and October for years 2003 and 2007 under all-sky conditions reveal very little bias $\left(-2.5 \mathrm{~W} \cdot \mathrm{m}^{-2}\right)$ and an RMS error of about $75 \mathrm{~W} \cdot \mathrm{m}^{-2}(21 \%)$ overall in the instantaneous net surface SW flux. Corresponding numbers for the CERES Model B product are $17 \mathrm{~W} \cdot \mathrm{m}^{-2}(3.5 \%)$ and $90 \mathrm{~W} \cdot \mathrm{m}^{-2}(19 \%)$. Results under clear-sky conditions reveal a slight negative bias of $-18 \mathrm{~W} \cdot \mathrm{m}^{-2}(-4 \%)$ and $-7 \mathrm{~W} \cdot \mathrm{m}^{-2}$ $(-1.5 \%)$ for the GOES-retrievals and CERES product respectively with RMS errors of about $45 \mathrm{~W} \cdot \mathrm{m}^{-2}$ $(8 \%)$ for both. Several locations display larger bias errors of about $20 \%$ during the snow-covered winter months. Yet, the performance of the algorithm presented here is comparable or even better than many similar studies reported in Table 4. Validation results are significantly better over homogeneous landscape in terms of surface albedo and vegetation density, for which ground measurements are more representative of the satellite pixel scale. Because spatial representativeness is quite difficult to compensate for, quantitative assessment of algorithm uncertainties requires dedicated and high quality in situ measurements over largely homogeneous sites.

The overall accuracy has been assessed through a comprehensive comparison between results of the parameterization and ground-based observations without restrictions on atmospheric, cloud and surface conditions. Error analysis reveals that the narrowband to broadband conversion of TOA flux is the major contributor to the uncertainty of results ranging from $5 \%$ to $10 \%$. Aerosol and water vapor uncertainties contribute about $3 \%$ and $1 \%$ respectively to the errors in the derived instantaneous values of net surface flux. A future study will consider enhancing the accuracy of the narrowband to broadband conversions through considering additional scene types, and extending the study to other regions making use of the network of geostationary meteorological satellites around the globe. One of the primary advantages and a major strength of using surface net radiation products from geostationary satellites is the significantly enhanced spatial and temporal resolution than that offered by the CERES instrument. However, this study highlights the need for high quality aerosol optical depth estimates over land at high spatial and temporal scales to enhance the accuracy of the surface net SW flux derived from satellite. 


\section{Acknowledgements}

This work was supported by NOAA through the Cooperative Institute for Climate and Satellites (CICS) - North Carolina under Cooperative Agreement NA09NES4400006, and by the Jet Propulsion Laboratory, California Institute of Technology, Pasadena, CA, under contract with the National Aeronautic and Space Administration (NASA). The GOES data are distributed by the NOAA's Comprehensive Large-Array Data Stewardship System (CLASS). The CERES data were obtained from the Atmospheric Sciences Data Center at the NASA Langley Research Center. The ARM/SGP and SURFRAD data were obtained from the Surface Observations provided by the CERES/ARM Validation Experiment (CAVE) web site. Authors are grateful for constructive comments provided by the reviewers which helped a great deal in improving the quality of presentation. Authors acknowledge the help rendered by Jessica Griffin (CICS) with figures.

\section{Author Contributions}

Anand Inamdar conceived and developed the methodology, validation strategy and performed most of the analysis. Pierre Guillevic conducted the detailed uncertainty analysis relating to the validity of point measurements. Anand Inamdar prepared bulk of the initial manuscript, while Pierre Guillevic wrote the section on spatial representativeness of ground-based measurements. Both authors contributed to the writing and final editing of the manuscript.

\section{Conflicts of Interest}

The authors declare no conflict of interest.

\section{References}

1. Stephens, G.L.; Wild, J.L.M.; Clayson, C.A.; Loeb, N.G.; Kato, S.; L’Ecuyer, T.; Stackhouse, P.W.; Lebsock, M.; Andrews, T. An update on earth's energy balance in light of the latest global observations. Nat. Geosci. 2012, 5, 691-696.

2. Liang, S.; Wang, K.; Zhang, X.; Wild, M. Review on estimation of land surface radiation and energy budgets from ground measurement, remote sensing and model simulations. IEEE J. Sel. Top. Appl. Earth Obs. Remote Sens. 2010, 3, 225-240.

3. Gilgen, H.; Ohmura, A. The global energy balance archive. Bull. Am. Meteor. Soc. 1999, 80, 831-850.

4. Ohmura, A.; Dutton, E.G.; Forgan, B.; Frohlich, C.; Gilgen, H.; Hegner, H.; Heimo, A.; Konig-Langlo, G.; McArthur, B.; Muller, G.; et al. Baseline surface radiation network (BSRN/WCRP): New precision radiometry for climate research. Bull. Am. Meteor. Soc. 1998, 79, 2115-2136.

5. Augustine, J.A.; Deluisi, J.J.; Long, C.N. SURFRAD—A national surface radiation budget network for atmospheric research. Bull. Am. Meteor. Soc. 2000, 81, 2341-2357.

6. Tarpley, J.D. Estimating incident solar radiation at the surface from geostationary satellite data. J. Appl. Meteor. 1979, 18, 1172-1181. 
7. Gautier, C.; Diak, G.R.; Masse, S. An investigation of effects of the spatially averaging satellite brightness measurements on the calculation of insolation. J. Clim. Appl. Meteor. 1984, 23, 1380-1386.

8. Diak, G.R.; Gautier, C. Improvements to a simple physical model for estimating insolation from GOES data. J. Clim. Appl. Meteor. 1983, 22, 505-508.

9. Darnell, W.L.; Staylor, W.F.; Gupta, S.K.; Denn, F.M. Estimation of surface insolation using sun-synchronous satellite data. J. Clim. 1988, 1, 820-835.

10. Pinker, R.T.; Lasszlo, I. Modeling surface solar irradiance for satellite applications on global scale. J. Appl. Meteor. 1992, 31, 194-211.

11. Perez, R.; Ineichen, P.; Moore. K.; Kmiecik, M.; Chain, C.; George, R.; Vignola, F. A new operational satellite-to-irradiance model-Description and validation. Sol. Energy 2002, 73, 307-317.

12. Zheng, T.; Liang, S.; Wang, K.C. Estimation of incident PAR from GOES imagery. J. Appl. Meteor. Clim. 2008, 47, 853-868.

13. Schmetz, J. Towards a surface radiation climatology. Retrieval of downward irradiance from satellites. Atmos. Res. 1989, 23, 287-321.

14. Schmetz, J. Retrieval of surface radiation fluxes from satellite data. Dyn. Atmos. Ocean. 1991, 16, $61-72$.

15. Zhang, Y.C.; Rossow, W.B.; Lacis, A.A.; Oinas, V.; Mischenko, M.I. Calculation of radiative fluxes from the surface to top of atmosphere based on ISCCP and other global data sets: Refinements of the radiative transfer model and the input data, J. Geophys. Res. 2004, 109, D19105.

16. Pinker, R.T.; Tarpley, J.D.; Laszlo, I.; Mitchell, K.E.; Houser, P.R.; Wood, E.F.; Schaake, J.C.; Robock, A.; Lohmann, D.; Cosgrove, B.A.; et al. Surface radiation budgets in support of the GEWEX Continental-Scale International Project (GCIP) and the GEWEX Americas Prediction Project (GAPP), including the North American Land Data Assimilation System (NLDAS) project. J. Geophys. Res. 2003, 108, doi:10.1029/2002JD003301.

17. Otkin, J.A.; Anderson, M.C.; Mecikalski, J.R.; Diak, G.R. Validation of GOES-based insolation estimates using data from the U.S. Climate Reference Network. J. Hydrometeor. 2005, 6, 460-475.

18. Pinker, R.T.; Frouin, R.; Li, Z. A review of satellite methods to derive surface shortwave irradiance. Remote Sens. Environ. 1995, 51, 105-124.

19. Jacobowitz, H.; Tighe, R.J. The earth radiation budget derived from the Nimbus-7 ERB experiment. J. Geophys. Res. 1984, 89, 4997-5010.

20. Barkstrom, B.R.; Smith, G.L. The earth radiation budget experiment: Science and implementation. Rev. Geophys. 1986, 24, 379-390.

21. Wielicki, B.A.; Barkstrom, B.R.; Baum, B.A.; Charlock, T.P.; Green, R.N.; Kratz, D.P.; Lee, B.I.; Minnis, P.; Smith, G.L.; Wong, T.; et al. Clouds and the Earth's Radiant Energy System (CERES): Algorithm overview. IEEE Trans. Geosci. Remote Sens. 1998, 36, 1127-1141.

22. Loeb, N.G.; Kato, S.; Loukachine, K.; Smith, N.M.; Doelling, D.R. Angular distribution models for top-of-atmosphere radiative flux estimation from the clouds and the Earth's radiant energy system instrument on the terra satellite. Part I: Methodology. J. Atmos. Ocean. Technol. 2005, 22, $338-351$. 
23. Li, Z.; Leighton, H.G.; Cess, R.D. Surface net solar radiation estimated from satellite measurements: Comparisons with tower observations. J. Clim. 1993, 6, 1764-1772.

24. Tang, B.; Li, Z.L.; Zhang, R. A direct method of estimating net surface shortwave radiation from MODIS data. Remote Sens. Environ. 2006, 103, 115-126.

25. Wang, D.; Liang, S.; He, T. Mapping high-resolution surface shortwave net radiation from Landsat data. IEEE Geosci. Remote Sens. Lett. 2014, 11, 459-463.

26. Masuda, K.; Leighton, H.G.; Li, Z. A new parameterization for the determination of solar flux absorbed at the surface from satellite measurements. J. Clim. 1995, 8, 1615-1629.

27. Augustine, J.A.; Hodges, G.B.; Cornwall, C.R.; Michaisky, J.J.; Medina, C.I. An update on SURFRAD - The GCOS surface radiation budget network for the continental United States. J. Atmos. Ocean. Technol. 2005, 22, 1460-1472.

28. Gupta, S.K.; Kratz, D.P.; Stackhouse, P.W.; Wilber, A.C. The Langley Parameterized Shortwave Algorithm (LPSA) for Surface Radiation Budget Studies (Version 1.0); Rep. NASA/TP-2001-211272; The NASA Scientific and Technical Information (STI) Program Office, Langley Research Center: Hampton, VA, USA, 2001.

29. Kratz D.P.; Gupta, S.K.; Wilber, A.C.; Sothcott, V.E. Validation of the CERES edition 2B surface-only flux algorithms. J. Appl. Meteor. Clim. 2009, 49, 164-180.

30. Augustine, J.A.; Hodges, G.B.; Dutton, E.G.; Michalsky, J.J.; Cornwall, C.R. An aerosol optical depth climatology for NOAA's national surface radiation budget network (SURFRAD). J. Geophys. Res. 2008, 113, D11204-D11216.

31. Kinne, S.; Schulz, M; Textor, C.; Guibert, S.; Balkanski, Y.; Bauer, S.; Berntsen, T.; Berglen, T.; Boucher, O.; Chin, M.; et al. An AeroCom initial assessment-Optical properties in aerosol component modules of global models. Atmos. Chem. Phys. 2006, 6, 1815-1834.

32. Wang, Z.; Schaaf, C.B.; Strahler, A.H.; Chopping, M.J.; Roman, M.O.; Shuai, Y.; Woodcock, C.E.; Hollinger, D.Y.; Fitzgerald, D.R. Evaluation of MODIS albedo product (MCD43A) over grassland, agriculture and forest surface types during dormant and snow-covered periods. Remote Sens. Environ. 2014, 140, 60-77.

33. Wang, L.; Daren, L.; Quing, H.E. The impact of surface properties on downward surface shortwave radiation over the Tibetan Plateau. Adv. Atmos. Sci. 2015, 32, 759-771.

34. Li, Z.; Cribb, M.C.; Chang, F.; Trischenko, A.; Luo, Y. Natural variability and sampling errors in solar radiation measurements for model validation over the atmospheric radiation measurement Southern Great Plains Region. J. Geophys. Res. 2005, 110, 1-11.

35. Guillevic, P.C.; Biard, J.H.; Privette, G.C.; Hook, J.L.; Olioso, S.J.; Gottsche, A.; Radocinski, F.-M.; Roman, R.; Yu, M.O.; Csiszar, I. Validation of Land Surface Temperature products derived from the Visible Infrared Imager Radiometer Suite (VIIRS) using ground-based and heritage satellite measurements. Remote Sens. Environ. 2014, 154, 19-37.

36. Guillevic, P.C.; Privette, J.L.; Coudert, B.; Palecki, M.A.; Demarty, J.; Ottle, C.; Augustine, J.A. Land Surface Temperature product validation using NOAA's surface climate observation networks - Scaling methodology for the Visible Infrared Imager Radiometer Suite (VIIRS). Remote Sens. Environ. 2012, 124, 282-298. 
37. Li, Z.; Leighton, H.G. Narrowband to broadband conversion with spatially autocorrelated reflectance measurements. J. Appl. Meteor. 1992, 31, 421-432.

38. Roman, R.; Bilbao, J.; Miguel, A. Uncertainty and variability in satellite-based water vapor column, aerosol optical depth and Angstrom exponent, and its effect on radiative transfer simulations in the Iberian Peninsula. Atmos. Environ. 2014, 89, 556-569.

(C) 2015 by the authors; licensee MDPI, Basel, Switzerland. This article is an open access article distributed under the terms and conditions of the Creative Commons Attribution license (http://creativecommons.org/licenses/by/4.0/). 